\title{
A General Parameter Identification Procedure Used for the Comparative Study of Supercapacitors Models
}

\author{
Henry Miniguano *®) Andrés Barrado $₫$, Cristina Fernández $₫$, Pablo Zumel and Antonio Lázaro \\ Power Electronics Systems Group; Universidad Carlos III de Madrid, 28911 Leganés, Spain; \\ barrado@ing.uc3m.es (A.B.); cfernand@ing.uc3m.es (C.F.); pzumel@ing.uc3m.es (P.Z.); \\ alazaro@ing.uc3m.es (A.L.) \\ * Correspondence: hminiguano@gmail.com; Tel.: +34-916-24-9188
}

Received: 22 March 2019; Accepted: 7 May 2019; Published: 10 May 2019

\begin{abstract}
Supercapacitors with characteristics such as high power density, long cycling life, fast charge, and discharge response are used in different applications like hybrid and electric vehicles, grid integration of renewable energies, or medical equipment. The parametric identification and the supercapacitor model selection are two complex processes, which have a critical impact on the system design process. This paper shows a comparison of the six commonly used supercapacitor models, as well as a general and straightforward identification parameter procedure based on Simulink or Simscape and the Optimization Toolbox of Matlab ${ }^{\circledR}$. The proposed procedure allows for estimating the different parameters of every model using a different identification current profile. Once the parameters have been obtained, the performance of each supercapacitor model is evaluated through two current profiles applied to hybrid electric vehicles, the urban driving cycle (ECE-15 or UDC) and the hybrid pulse power characterization (HPPC). The experimental results show that the model accuracy depends on the identification profile, as well as the robustness of each supercapacitor model. Finally, some model and identification current profile recommendations are detailed.
\end{abstract}

Keywords: supercapacitor models; parameter estimation; ECE15; HPPC; Simulink; Simscape; Matlab; Identification

\section{Introduction}

Energy storage systems are essential in the industrial, medical, renewable or transportation sectors, as well as other sectors. Some characteristics like high power density, reliability and safety are critical in those sectors, this is why the electrochemical double layer capacitor or the supercapacitor play an important role [1].

Many application areas in which supercapacitors are used can be mentioned like magnetic resonance imaging (MRI) that needs very short pulses with high current [2] or fuel cell supercapacitor hybrid bus, where the supercapacitor satisfy the dynamic power demand [3]. In addition, the supercapacitor can be used for the integration of a photovoltaic power plant [4], grid integration of renewable energies [5] and the improvement of energy utilization for mine hoist applications [6]. However, many applications are limited by the self-discharge behavior in wireless sensor network applications [7], where the new techniques of chemical modification to suppress this phenomenon are shown in reference [8] and reference [9].

In general, the supercapacitors models classify into three categories: electrochemical, mathematical, and electrical. Electrochemical models consist of a set of partial differential-algebraic equations with many parameters. The estimation of the electrochemical model is very accurate [10]. However, the simulation of these models consumes many resources. Mathematical models are an alternative based on three dimensional ordered structures [11]. It can get a good fitting with 
experimental data but with a complex process to get the different parameters. Finally, circuit-based or electrical models are able to reproduce the electrical behavior of supercapacitors with equivalent circuits [12].

In the literature, there are some studies comparing supercapacitor models. Reference [13] reviews three types of equivalent circuits with linear components, with only an identification current profile and several verification current profiles. These models are the classic model, the multi-stage ladder model, and the dynamic model, which are used in electric vehicle applications. In this case, a genetic algorithm (GA) is used to estimate the different constant parameters of the resistors and capacitors $(R C)$ circuits. Reference [14] analyzes three basic constant parameters RC networks models showing the relationship among them. However, as shown in reference [15], the model accuracy can be improved with a nonlinear equivalent circuit model. In reference [16], the authors compared three circuits models (Miller Model, Zubieta Model, and Thevenin Model) with a specific identification current profile for every model. In general, the papers found in the state-of-the-art compare some of the known supercapacitor models, applying different identification current profiles, and using different parameters identification procedures, as it is difficult to obtain reliable conclusions to identify the best model for every application.

The main contribution of this paper is the proposal of a general, practical and effective parameters identification procedure applied to supercapacitors models and obtained in offline mode. The parameters of this model can also be used as an initial estimation of the parameters in online supercapacitor models [17]. The numeric optimization is developed by means of the interactive interface provided by the Identification Toolbox of Matlab (Version R2018b, MathWorks, Natick, MA, USA), once the equivalent models are built in Simulink or Simscape. In addition, the paper shows the comparison of different identification current profiles applied to six kinds of models in order to obtain the best features of each model, as well as the best accurate vs. complexity model.

The next sections are organized as follows: Section 2 shows the six supercapacitor models selected to make the comparative study, as well as their circuits implemented in Simulink or Simscape. Section 3 describes the parameters estimation procedure. Section 4 depicted the different current profiles and the experimental setup to get the supercapacitor voltage and current responses. Section 5 shows the obtained statistical metrics using ECE15 and HPPC dynamic driving cycles, and the discussion about the experimental vs. simulation results. Finally, in Section 6, the main conclusions are presented.

\section{Supercapacitors Models}

In this section, six representative supercapacitor models are selected from the literature, which cover most of the typical applications. All of them are nonlinear models since this kind of models obtains better accuracy. The selected models are the Stern-Tafel Model [18], Zubieta Model [19], Series Model [20], Parallel Model [21], Transmission Line Model [22] and Thevenin Model [23]. In this section, the electrical equivalent circuit and the parameters of each model are reviewed.

\subsection{Stern-Tafel Model}

The supercapacitor proposed in reference [24] and reference [25] uses the Stern-Tafel model to describe the nonlinear capacitance. This electrochemical model reproduces the double layer capacitance $\left(C_{T}\right)$ related to the nonlinear diffusion dynamics. To do this, the supercapacitor model combines both the Helmholtz's capacitance $\left(C_{H}\right)$ and Gouy-Chapman's capacitance $\left(C_{G C}\right)$ [26],

$$
C_{T}=\frac{N_{p}}{N_{s}} \cdot\left(\frac{1}{C_{H}}+\frac{1}{C_{G C}}\right)^{-1}
$$

Being

$$
C_{H}=\frac{N_{e} \cdot \varepsilon \cdot \varepsilon_{0} \cdot A_{i}}{d}
$$




$$
C_{G C}=\frac{F \cdot Q_{T}}{2 \cdot N_{e} \cdot R \cdot T} \sinh \left(\frac{Q_{T}}{N_{e}^{2} \cdot A_{i} \sqrt{8 \cdot R \cdot T \cdot \varepsilon \cdot \varepsilon_{0} \cdot C}}\right)
$$

where $N_{p}$ is the number of parallel supercapacitor cells, $N_{s}$ is the number of series of supercapacitor cells, $N_{e}$ is the number of layers of electrodes, $d$ the molecular radius $(\mathrm{m}), c$ the molar concentration $\left(\mathrm{mol} . \mathrm{m}^{-3}\right)$, $A_{i}$ is the interfacial area between electrode and electrolyte $\left(\mathrm{m}^{2}\right), T$ is the operating temperature $(\mathrm{K}), F_{c}$ is the Faraday constant $(\mathrm{C} / \mathrm{mol}), R$ is the ideal gas constant $(\mathrm{J} /(\mathrm{K} \cdot \mathrm{mol})), \varepsilon$ is the relative permittivity of the electrolyte material $(\mathrm{F} / \mathrm{m})$, and $\varepsilon_{0}$ is the free space permittivity $(\mathrm{F} / \mathrm{m})[18]$.

The model equivalent circuit has a controlled voltage source and an internal resistance, as shown in Figure 1a. This model depends on several parameters where $C_{n}$ is the nominal capacitance (F), $V_{\max }$ is the maximum supercapacitor voltage $(\mathrm{V}), R_{d c}$ is the internal resistance $(\Omega), V_{T}$ is the total voltage $(\mathrm{V})$, and $i_{s d}$ is the self-discharge current (A) which is determined by the Tafel Equation (4) described in reference [27] as:

$$
i_{s d}(t)=N_{e} \cdot I_{f} \cdot e^{\left(\frac{\alpha \cdot F_{c} \cdot\left(\frac{V_{\text {init }}}{N_{s}}-\frac{V_{\text {max }}}{N_{s}}-\Delta V\right)}{R \cdot T}\right)}
$$

where $I_{f}$ is the leakage current $(\mathrm{A}), V_{\text {init }}$ is the initial voltage $(\mathrm{V}), \alpha$ is the charge transfer coefficient and $\Delta V$ is the over-potential $(\mathrm{V})$. The capacitance of the electrochemical model requires only a few data from manufacturer datasheet and universal constant as described in reference [28]. The Simulink implementation is shown in Figure $1 b$.

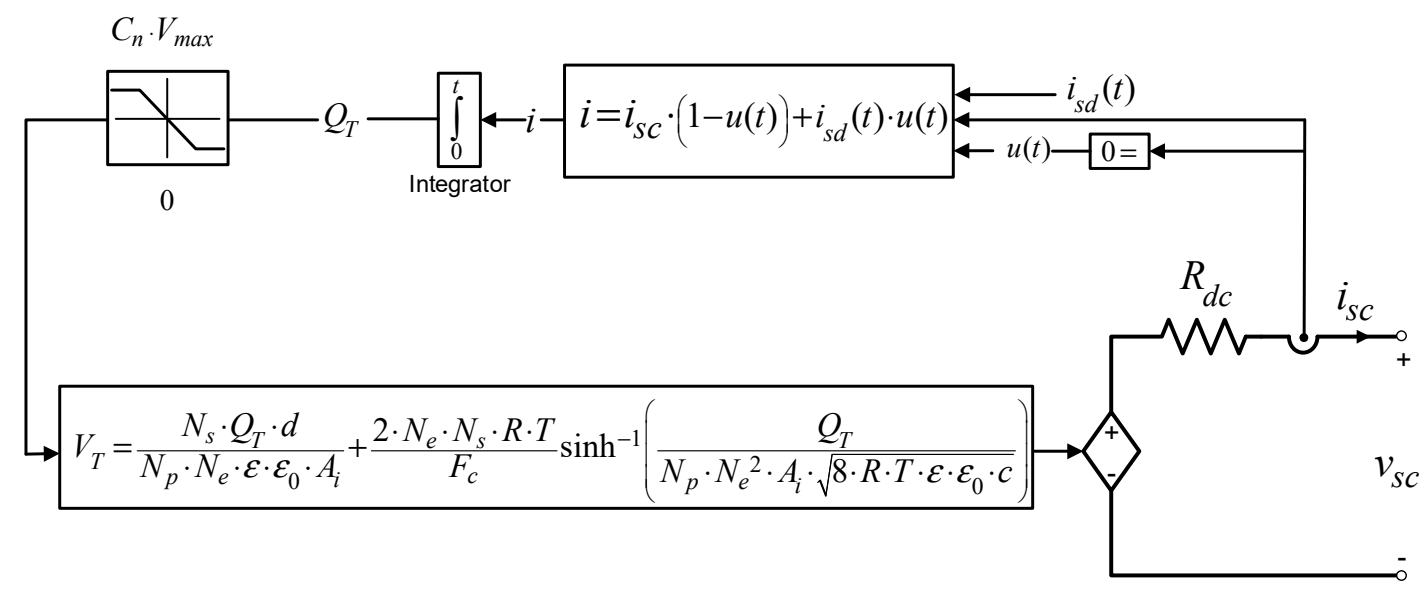

(a)

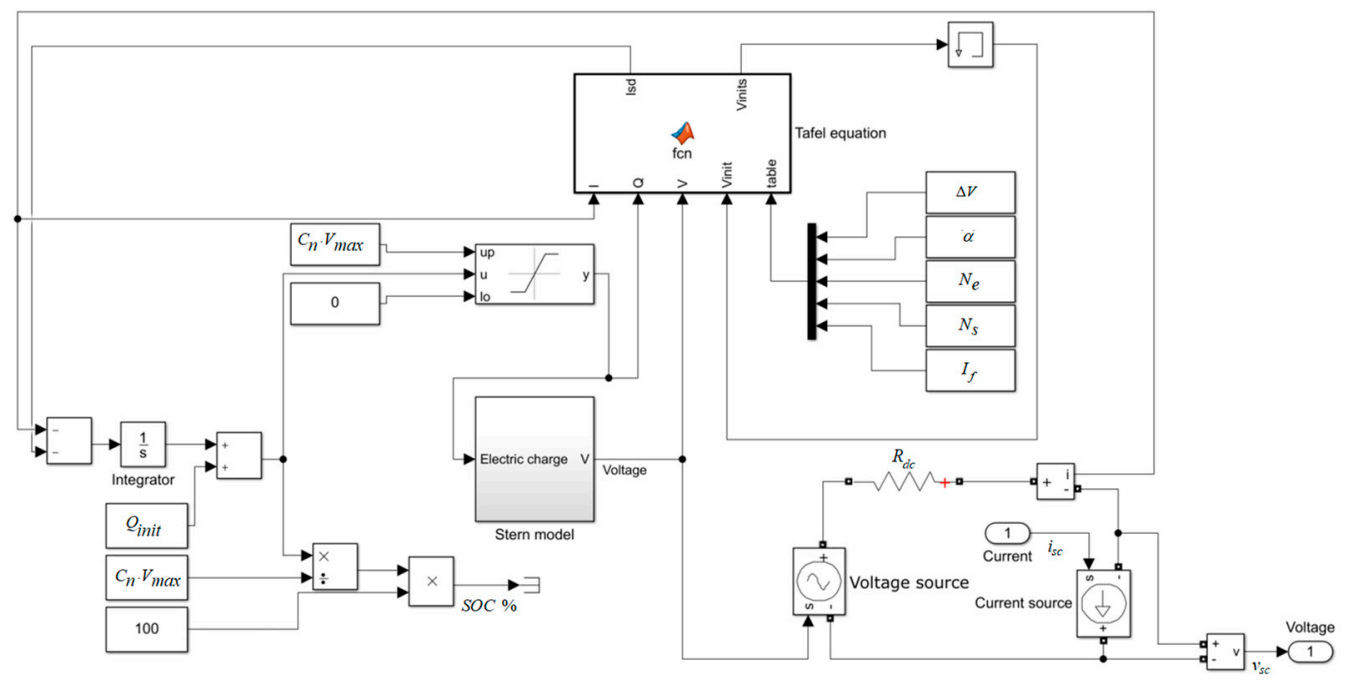

(b)

Figure 1. Stern-Tafel model: (a) Electric circuit; (b) Simulink implementation. 


\subsection{Zubieta Model}

The proposed model in reference [19] includes a circuit with three parallel $R C$ time constant, Figure 2a. The first branch, with the elements $R_{0} C_{0}$, and the voltage-dependent $k_{c} \cdot v_{c}$ defines the response in seconds. The second branch $R_{1} C_{1}$ provides the response in the range of minutes. The branch $R_{2} C_{2}$ represents the response for a time longer than minutes. Finally, a resistor $R_{l k}$ reproduces the leakage resistance.

A simplified equivalent circuit with two branches is shown in reference [29], with a simplified parameter identification procedure through the differential equation of the circuit. Similar studies are proposed in reference [30] in which the model parameters are easily obtained when the supercapacitor is discharged with constant power. In addition, reference [31] proposes a multivariable minimization function to find the parameters, they are validated with a current profile of a hybrid electric vehicle.

The total capacitance and current of the voltage-controlled capacitance implemented in Simscape are shown in Figure 2b, which are defined by (5) and (6):

$$
\begin{gathered}
C\left(v_{\mathcal{C}}\right)=C_{0}+k_{c} \cdot v_{\mathcal{C}} \\
i_{c}=\frac{d Q}{d t}=\frac{d\left(C\left(v_{\mathcal{c}}\right) \cdot v_{\mathcal{C}}\right)}{d t}=\left(C_{0}+2 k_{\mathcal{c}} \cdot v_{\mathcal{C}}\right) \frac{d v_{\mathcal{C}}}{d t}
\end{gathered}
$$

where $C_{0}$ is the initial linear capacitance which represents the electrostatic capacitance of the capacitor, and $k_{c}$ a positive coefficient which represents the effects of the diffused layer of the supercapacitor.

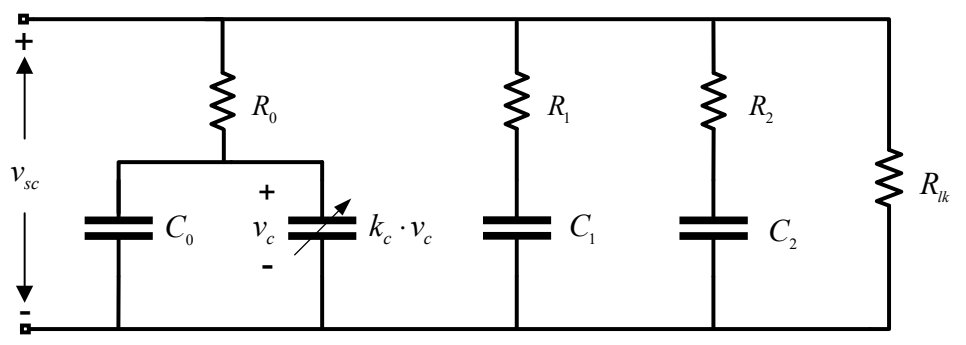

(a)

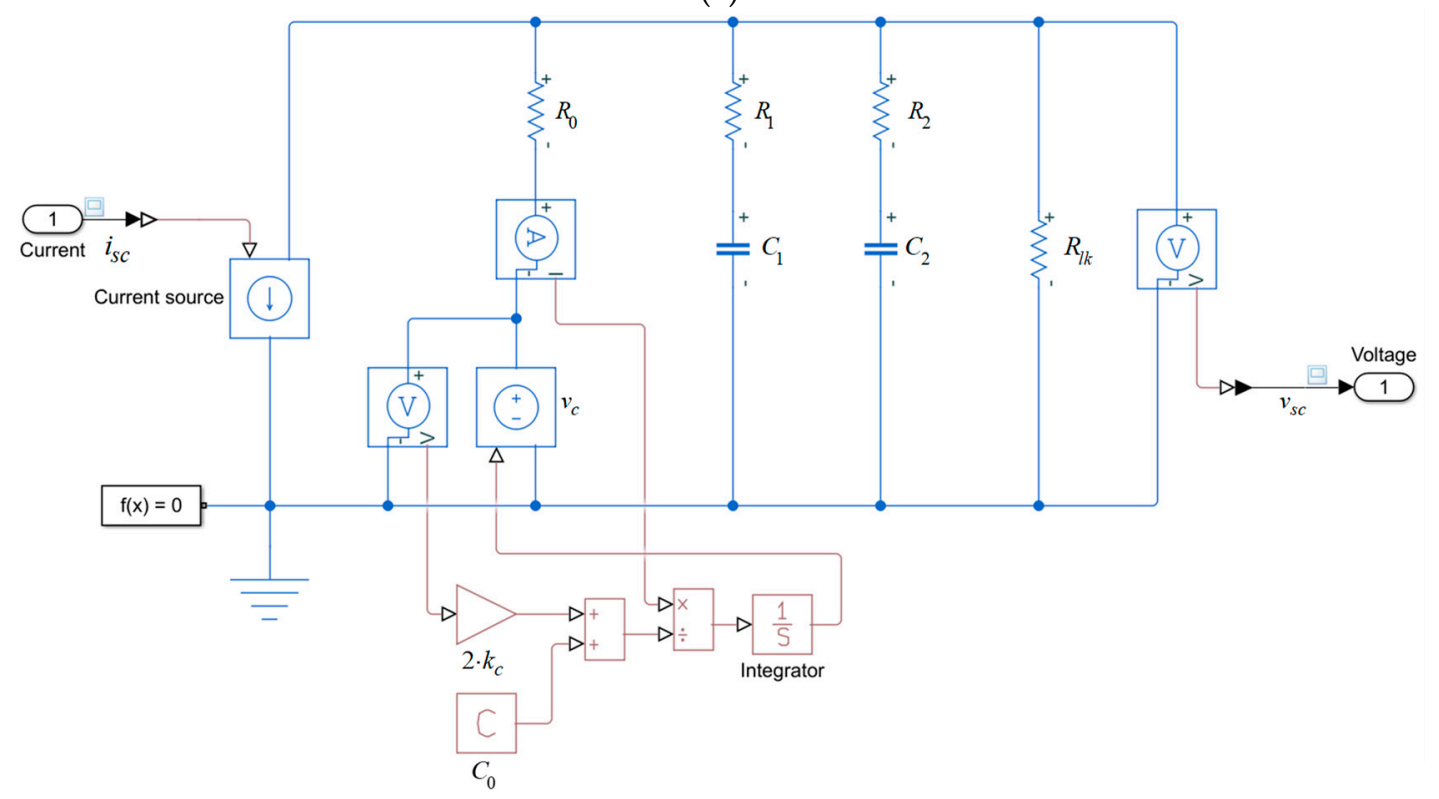

(b)

Figure 2. Zubieta model: (a) Electric circuit; (b) Simscape implementation. 


\subsection{Series Model}

The series model is an equivalent circuit obtained through the AC impedance approach, which consists of two parallel $R C$ circuit compound by $R_{1}(v s c), C_{1}(v s c), R_{2}(v s c), C_{2}(v s c)$, connected in series with another $R C$ circuit compound by $R_{s}$ and $C_{s}(v s)$, as described in references [20,32,33]. This equivalent circuit shows in the first branch of Figure 3a. In reference [34] a modified version of this circuit was presented, which includes the model proposed by Buller and Zubieta, in order to represent a complete model for a full frequency range. This complete model includes three branches in a parallel compound by $R_{3}$ and $C_{3}, R_{4}$ and $C_{4}$, and the leakage resistance $R_{l k}$, as shown in Figure 3a. Figure $3 \mathrm{~b}$ shows the Simscape implementation of the modified series model.

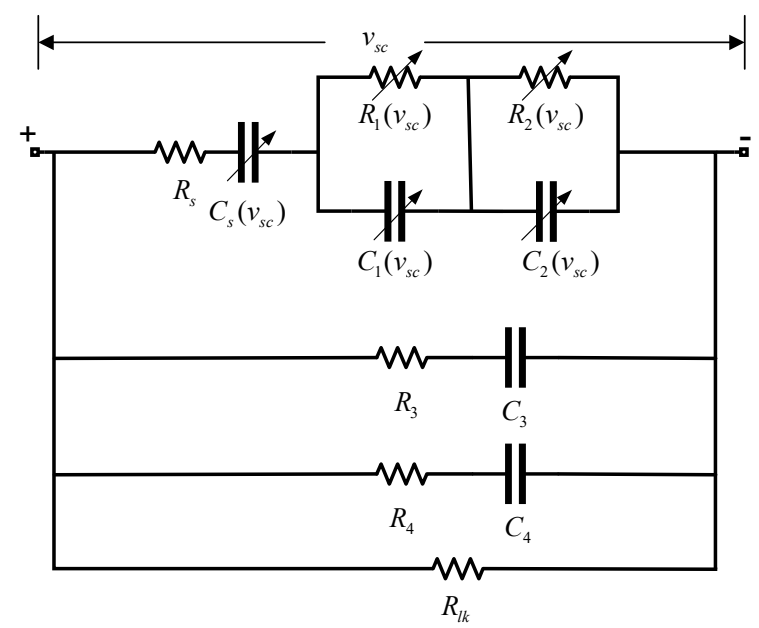

(a)

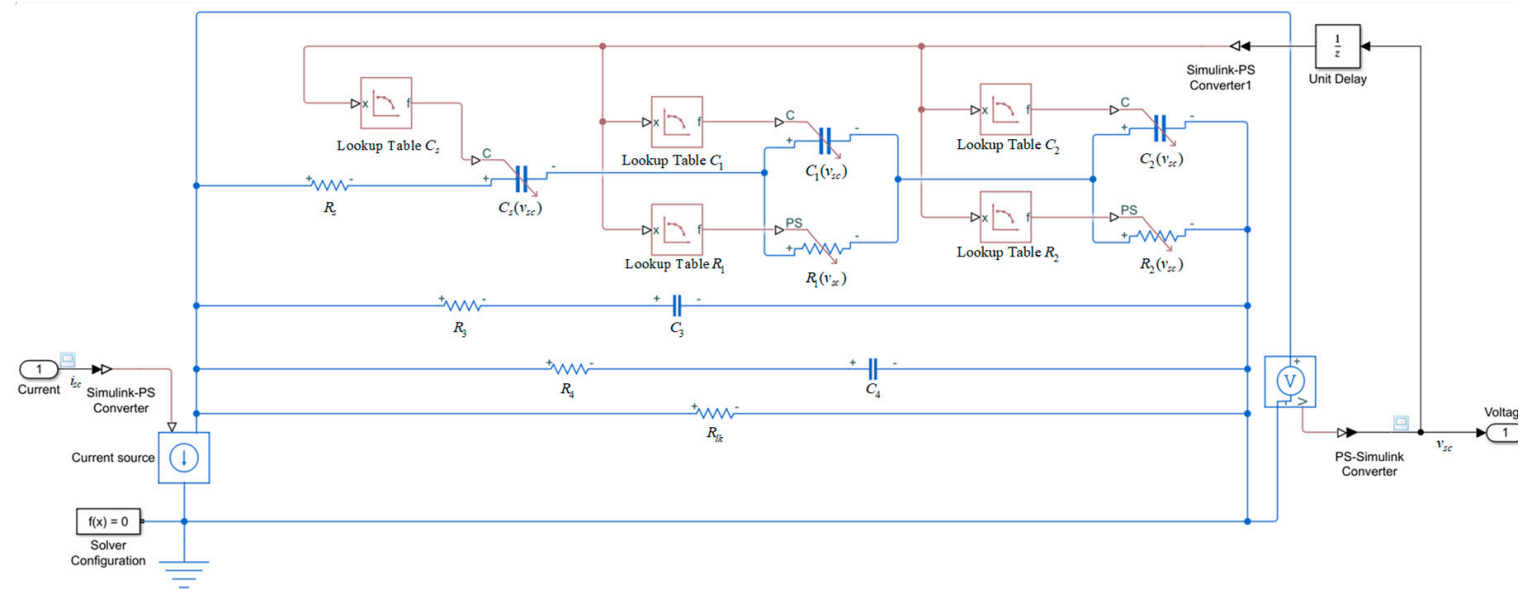

(b)

Figure 3. Series model: (a) Electric circuit; (b) Simscape implementation.

\subsection{Parallel Model}

The basic parallel model with constant values is described in reference [35] and reference [36]. Reference [37] describes an approximation to calculate the parameters without data acquisition, only using the information provided by a supercapacitor datasheet, as well as the main basic equations to obtain the constant parameters using this information. A modified four parallel $R C$ networks with voltage-dependent parameters are presented in reference [21], and it is shown in Figure 4a. This model is more complex, but it achieves better accuracy. Figure $4 \mathrm{~b}$ shows the implementations of the modified parallel model in Simscape. 


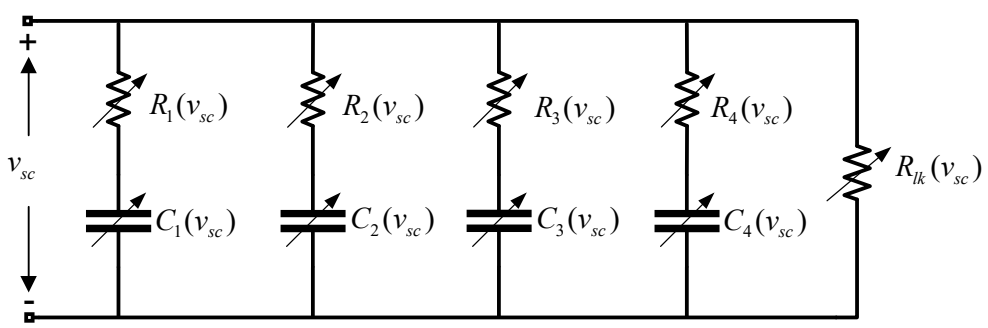

(a)

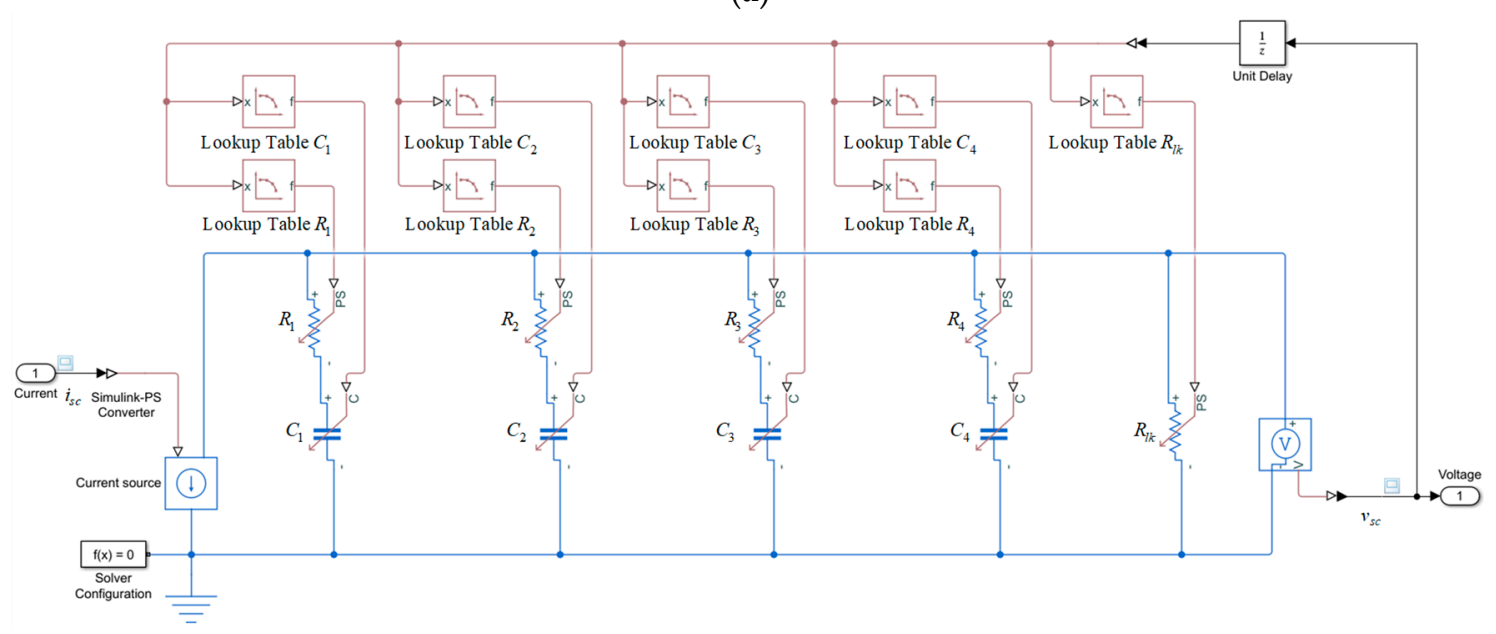

(b)

Figure 4. Series model: (a) Electric circuit; (b) Simscape implementation.

\subsection{Transmission Line Model}

Transmission line model is composed of $n R C$ branches in order to reproduce the supercapacitor frequency response from $10 \mathrm{mHz}$ to $1 \mathrm{kHz}$. This model was proposed for hybrid and electric vehicles, and it was described in reference [38] and reference [39]. This model consists of four parallel networks based on $R_{1}, C_{1}\left(v_{1}\right), R_{2}, C_{2}\left(v_{2}\right), R_{3}, C_{3}\left(v_{3}\right)$ and $R_{4}, C_{4}\left(v_{4}\right)$, and a parallel leakage resistance $R_{l k}$, as shown in Figure 5a. Reference [22] describes a procedure to estimate the parameters through time response and the equations of the circuit. Also, this model is used to evaluate the supercapacitor physical aging process [40], by estimating the uncertainties of the parameters. Reference [41] uses a different number of networks according to the simulation time step.

Figure $5 \mathrm{~b}$ shows the model implemented in Simscape with the described Equations (5) and (6).

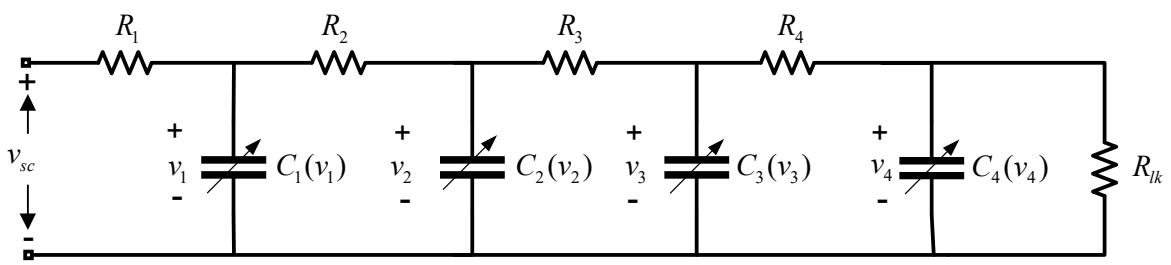

(a)

Figure 5. Cont. 


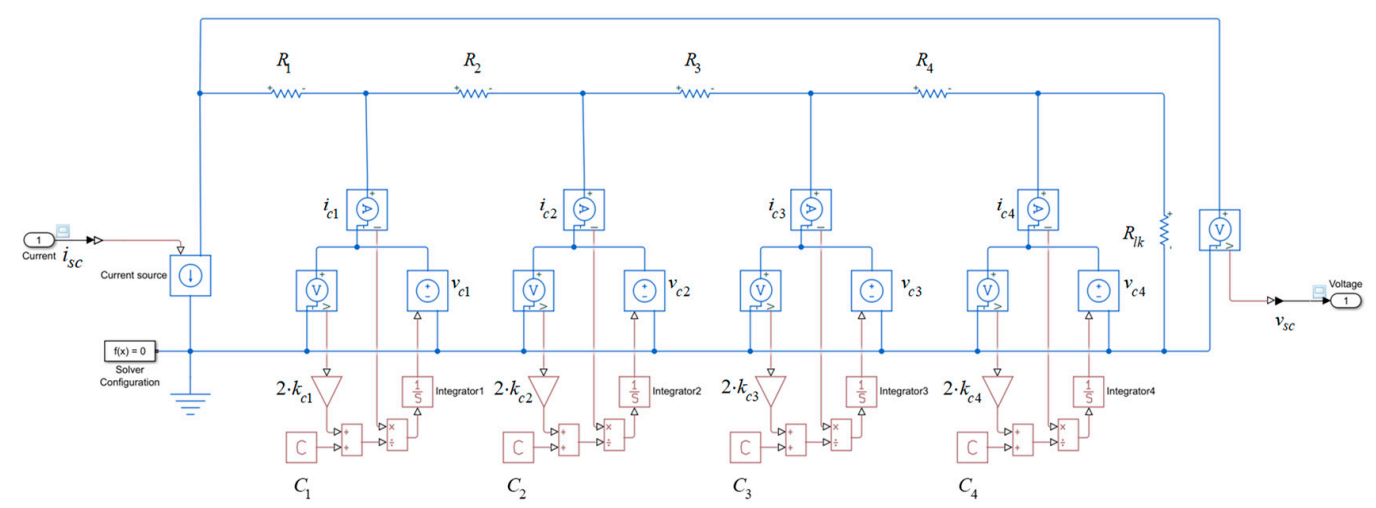

(b)

Figure 5. Series model: (a) Electric circuit; (b) Simscape implementation.

\subsection{Thevenin Model}

The equivalent electric circuit of the Thevenin model, which includes several parallel RC and a nonlinear state-of-charge (SOC) voltage-dependent source is described in reference [42]. The SOC is calculated by coulomb counting using (7):

$$
S O C=\frac{Q_{\text {init }}-\int_{0}^{t} i(\tau) d \tau}{Q_{T}}
$$

with $Q_{\text {init }}$ being the initial supercapacitor charge, $Q_{T}$ being the total supercapacitor charge and $i(\tau)$ as the supercapacitor current.

In this paper, three $R C$ branches are used to get a better accuracy, where $O C V$ represents the open circuit voltage, $R_{0}$ represents the internal resistance, and three parallel networks based on $R_{1}, C_{1}$, $R_{2}, C_{2}, R_{3}$, and $C_{3}$ reproduce the supercapacitor dynamic, as shown in Figure 6a. All parameters are state-of-charge dependent. The proposed model applied to a hybrid storage system for an electric vehicle gives a better agreement for a simulated vs. experimental response when 3-branches are used in the model [23]. Figure $6 \mathrm{~b}$ shows the Simscape implementation.

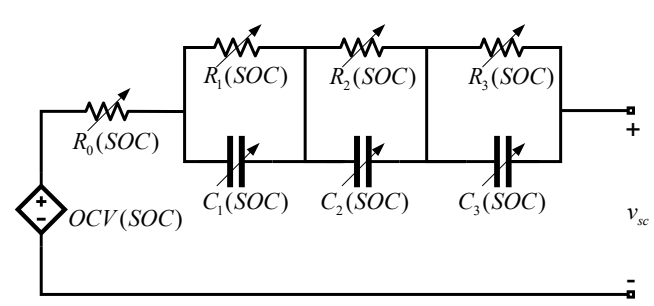

(a)

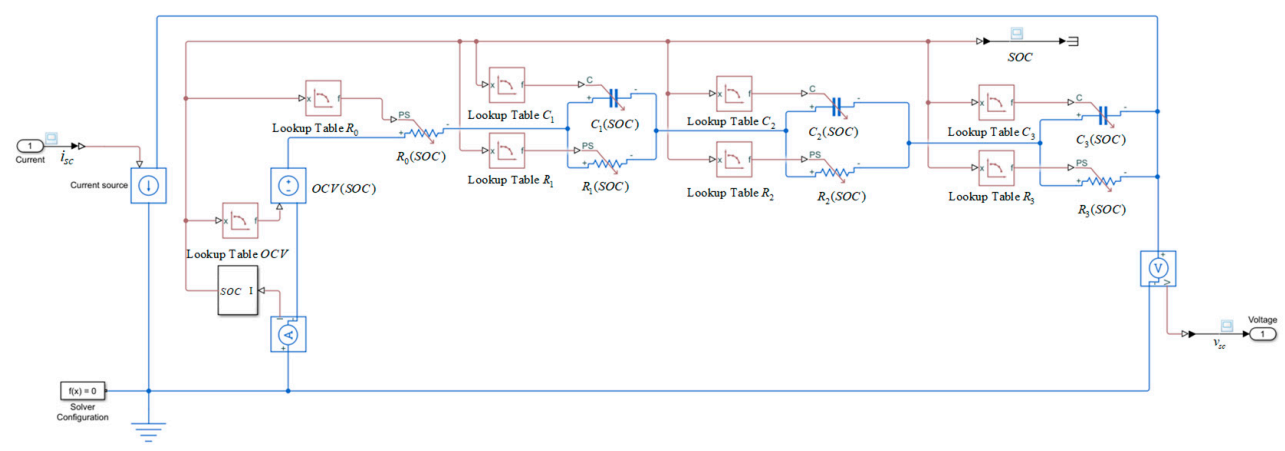

(b)

Figure 6. Series model: (a) Electric circuit; (b) Simscape implementation. 


\section{Parameters Estimation Procedure}

Parametric models explicitly contain differential equations, transfer function or block diagrams. The parameters update could be offline or online. For obtaining the parameters, in the offline mode, the data are stored to later process, on the other hand, in the online mode, the procedure is executed in parallel to the experiment [43]. In the literature, there are many proposed procedures to obtain the model parameters such as e.g., the unscented Kalman filter [44] or the Luenberger-style technique [17].

Taking into account the literature, this paper focuses on the proposal of a practical, interactive, simple and enough general offline procedures for estimating the model parameters.

Figure 7a shows the proposed identification procedure block diagram. This procedure can be divided into several steps, shown and described in Table 1.

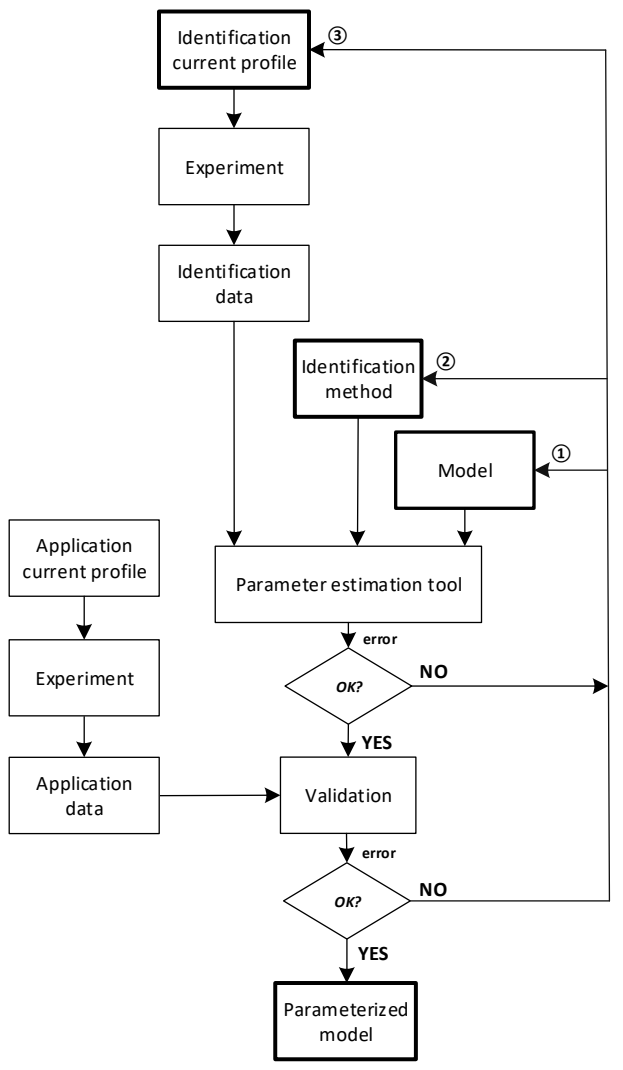

(a)

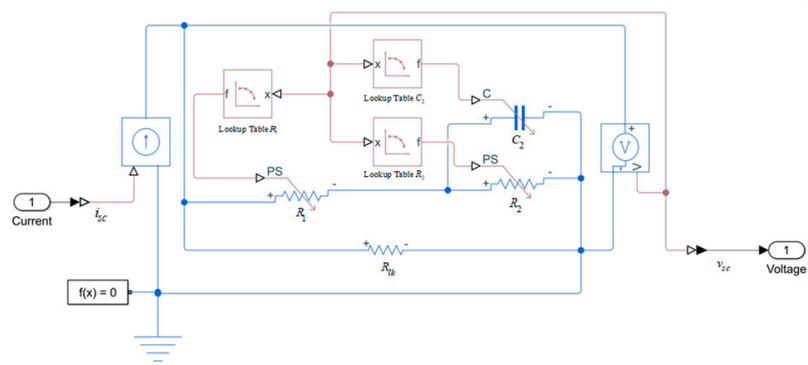

(b)

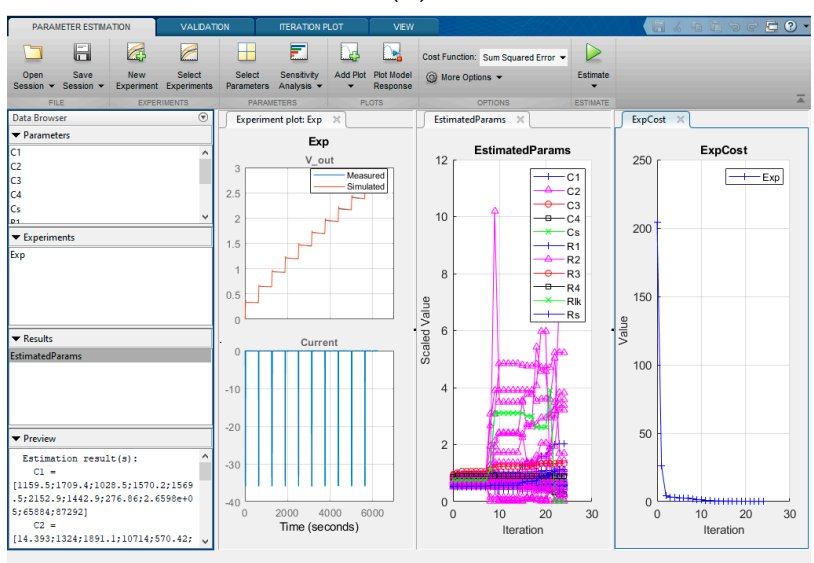

(c)

Figure 7. Parameter estimation procedure: (a) Identification block diagram process; (b) Simscape model; (c) Interactive interface by Simulink [45].

Table 1. Parameter Estimation Steps.

\begin{tabular}{|c|c|}
\hline Steps & Description \\
\hline 1 & $\begin{array}{l}\text { Apply the identification current profile to obtain supercapacitor current and voltage waveforms } \\
\text { (identification data) from the experimental test. E.g., as shown in Section 4.2: current profiles and } \\
\text { supercapacitor voltage response (a), (b) and (c). }\end{array}$ \\
\hline 2 & $\begin{array}{l}\text { Select and build the equivalent circuit model in Simulink or Simscape through a block diagram or } \\
\text { circuit. E.g., as shown in Section 3: Figure 7b. }\end{array}$ \\
\hline 3 & $\begin{array}{l}\text { Create a new experiment in Simulink and to import the identification data. Simulate the model with } \\
\text { the initial parameters and the identification current profile to obtain the simulation data. E.g., } \\
\text { as shown in Section 3: Figure 7c. }\end{array}$ \\
\hline 4 & Choose the variables and their limits to estimate their value. E.g., as shown in Section 3: Figure 7c. \\
\hline
\end{tabular}


Table 1. Cont.

\begin{tabular}{|c|c|}
\hline Steps & Description \\
\hline 5 & $\begin{array}{l}\text { Set up optimization options (optimization method, algorithm, and parameter and function tolerance). } \\
\text { E.g., as shown in Section 3: Figure } 8 .\end{array}$ \\
\hline 6 & $\begin{array}{l}\text { Run the parameter estimation process applying the selected optimization solver (E.g., sum-squared } \\
\text { error) to match the identification data with the simulation data. E.g., as shown in Section 3: Figure 7c. } \\
\text { If the error is not small enough, return to step } 1 \text { (1)); or change the identification method and return to } \\
\text { step } 3 \text { (2)); or modify the current profile and return to step } 2 \text { (3), Figure 7a. }\end{array}$ \\
\hline 7 & $\begin{array}{l}\text { Once the model parameters have been obtained from the identification data, the next step is to verify } \\
\text { the model response using the application current profile and the application data. For that, it is } \\
\text { necessary to compare the application data with the new simulated data, using the obtained } \\
\text { parameters in step 6, E.g., as shown in Section } 4.2 \text { : Figure } 9 \text { d,e. If the error is not small enough, return } \\
\text { to step } 1 \text { (1); or change the identification method and return to step } 3 \text { (2); or modify the current } \\
\text { profile and return to step } 2 \text { (3), Figure 7a. }\end{array}$ \\
\hline
\end{tabular}

In step 5, the optimization method has to be selected. This paper uses an offline parameters estimation based on the error minimization between the measured and simulated supercapacitor voltage. The iterative procedure tunes the supercapacitors model parameters $(p)$ to get a simulated response $\left(V_{s}\right)$ that tracks the measured response $\left(V_{m}\right)$, with a finite number of samples $(n)$. To do that, the solver minimizes the next cost function for each current profile:

$$
F(p)=\min _{p} \sum_{i=0}^{n}\left[V_{m_{i}}-V_{s_{i}}(p)\right]^{2}
$$

where $p$ varies between zero and infinity (e.g., 0 to $10^{10}$ ).

The minimization problem is carried out with Simulink ${ }^{\circledR}$ Design Optimization ${ }^{\mathrm{TM}}$ of Matlab (Version R2018b, MathWorks, Natick, MA, USA). This toolbox provides an interactive interface that helps to minimize the square of the error between the measured and simulated supercapacitor voltage, using the nonlinear least squares method for parameters estimation. This method is selected in the user interface as shown in Figure 8.

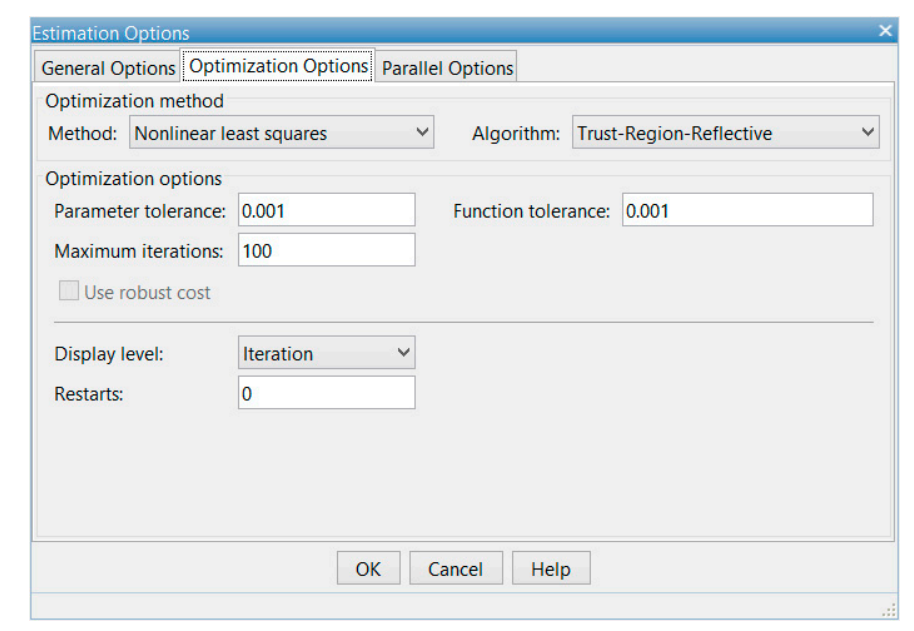

Figure 8. The optimization option user interface for parameter estimation.

This method uses the Simulink function named as lsqnonlin, that requires at least $(2 k+1)$ simulations per iteration, where $k$ is the number of parameters to be estimated [46]. The required CPU time and memory increase as a function of the numbers of parameters and their initial values. The offline runtime estimation is in the order of minutes. 
If runtime estimation has to be reduced, other techniques based on the layered technique to break the global optimization into a smaller task [47], or based on differential mutation strategy [48], or based on genetic programming [49], among others, could be used, although the flexibility and simplicity provided by the Simulink user interface could be affected.

On the other hand, the algorithm selected is the Trust-Region-Reflective, which is based on a gradient process with a trial step by solving a trust region. Specific details of the algorithm can be found in reference [45]. Additional information is detailed in reference [50], in which the process of how to import, analyze, prepare and estimate model parameters in Simulink is described.

Using the proposed procedure, based on Simulink ${ }^{\circledR}$ Design Optimization ${ }^{\mathrm{TM}}$ of Matlab, the most model can be built, from a practical point of view. Nevertheless, this procedure is limited by the optimization methods and algorithms included in Simulink.

\section{Experimental Setup}

\subsection{Supercapacitor Testing System}

The experimental setup includes a supercapacitor, a data acquisition system, a power source, and an electronic load, as shown in Figure 9. The supercapacitor used to develop the test has been the Maxwell BCAP3000. An equivalent bidirectional current source compound of the electronic load and the power source, connected in parallel, emulates the current profile. This equivalent current source includes the typical regenerative breaking present in automotive applications. The experimental current profile and the data acquisition system are conducted using the following set of equipment listed in Table 2:

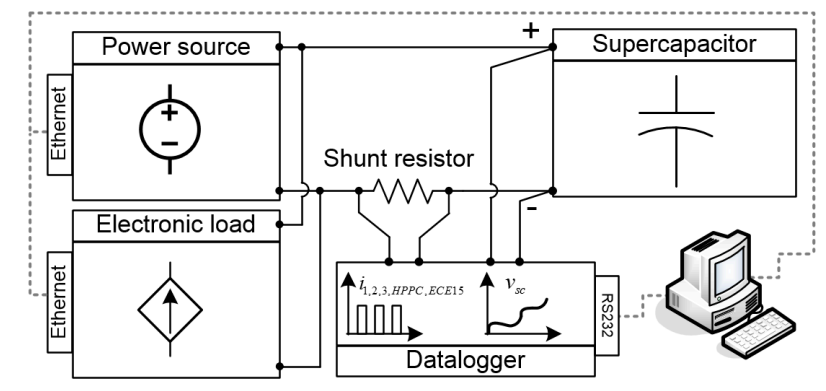

Figure 9. Experimental setup.

Table 2. Equipment and Components used in the Experimental Setup.

\begin{tabular}{ccc}
\hline Component & Specifications & Use \\
\hline Supercapacitor: Maxwell BCAP3000 & $2.7 \mathrm{~V} / 3000 \mathrm{~F}$ & Cell under test \\
Datalogger: Agilent 34970A & $100 \mathrm{nV}-1000 \mathrm{~V} / 500 \mathrm{kHz}$ & Measure voltage \\
Power source: Sorensen SGI400/38 & $400 \mathrm{~V} / 38 \mathrm{~A}$ & Current charge \\
Electronic load: Chroma 63206A-600 & $600 \mathrm{~V} / 420 \mathrm{~A}$ & Current discharge \\
Shunt resistor: Newtons4th HF200 & $0.5 \mathrm{~m} \Omega / 200 \mathrm{~mA} \rightarrow 200 \mathrm{Arms}$ & Measure current \\
\hline
\end{tabular}

All these elements have been synchronized with a computer running to manage the data logging and supervisory control using LabVIEW ${ }^{\circledR}$ software.

\subsection{Supercapacitor Test Schedule}

The parameter identification procedure uses three different current profiles. The current profile $i_{1}$ is a current step, Figure 10a; the current profile $i_{2}$ are repetitive charging current steps applied until to reach the maximum supercapacitor voltage, Figure 10b; and the current profile $i_{3}$ is a dynamic charge-discharge current step modulated in amplitude and time applied until the middle value of the supercapacitor voltage range, [51], Figure 10c. From the modeling perspective, the validation current profile must be more dynamic in amplitude and frequency than the identification current profile, as shown in Figure 10d,e. 


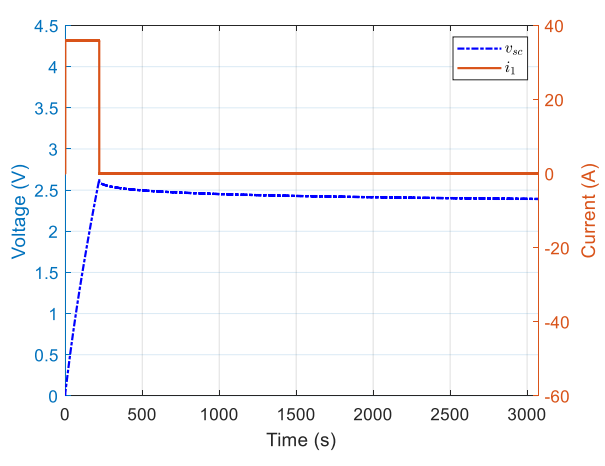

(a)

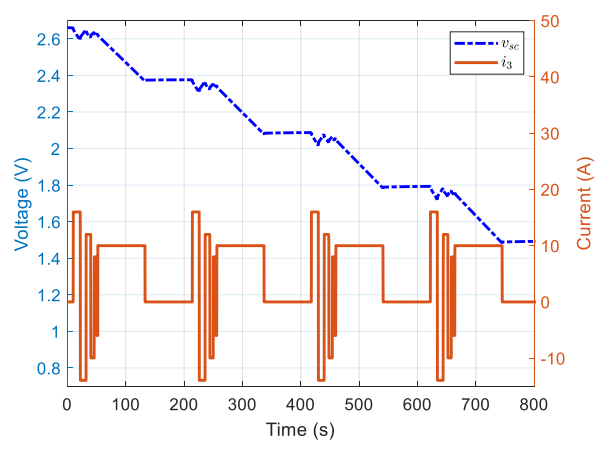

(c)

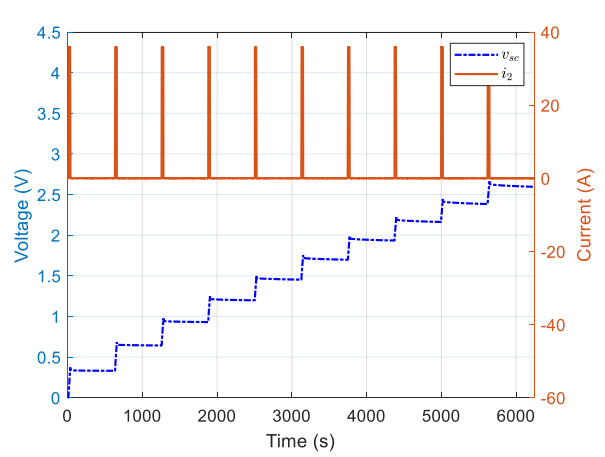

(b)

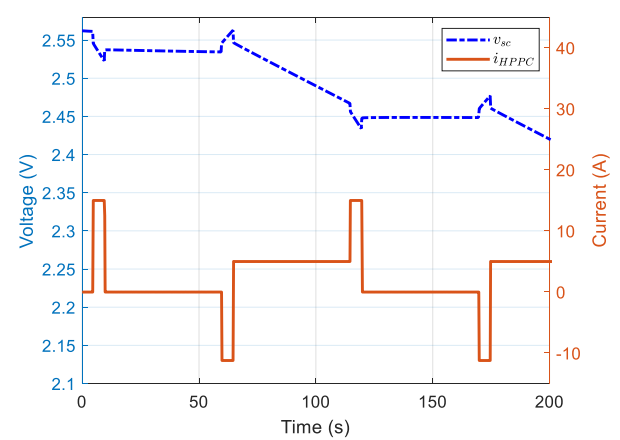

(d)

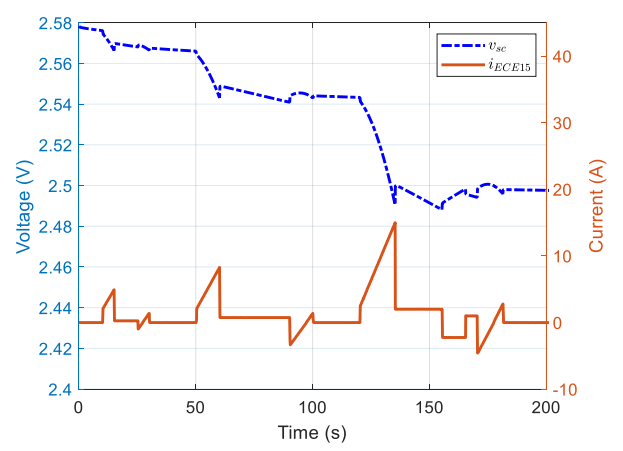

(e)

Figure 10. Current profiles and supercapacitor voltage response: (a) $i_{1} ;(\mathbf{b}) i_{2} ;(\mathbf{c}) i_{3} ;$ (d) Verification HPPC profile; (e) Verification ECE15 profile.

These identification current profiles apply to those models aforementioned in Section 2 to obtain their parameters. The current profile applied in every model is shown in Table 3.

The robustness and accuracy of the supercapacitor models are evaluated by means of different standardized test profiles, which include the Hybrid Pulse Power Characterization (HPPC) test and European Urban Driving Cycle (ECE15) for long-time responses. Figure 9d shows the HPPC test that is described in the Freedom Car Battery Manual [52]. The ECE15 test, described in reference [53], is a more dynamic current profile, as shown in Figure 10e. 
Table 3. Identification Current Profiles Used to Supercapacitor Parameters Estimation.

\begin{tabular}{lccc}
\hline \multirow{2}{*}{ Model } & \multicolumn{3}{c}{ Current Profile } \\
\cline { 2 - 4 } & $\boldsymbol{i}_{\mathbf{1}}$ & $\boldsymbol{i}_{\mathbf{2}}$ & $\boldsymbol{i}_{\mathbf{3}}$ \\
\hline Stern-Tafel & $\checkmark$ & - & - \\
Zubieta & $\checkmark$ & $\checkmark$ & $\checkmark$ \\
Series & - & $\checkmark$ & $\checkmark$ \\
Parallel & - & $\checkmark$ & $\checkmark$ \\
Transmission line & - & $\checkmark$ & $\checkmark$ \\
Thevenin & - & $\checkmark$ & $\checkmark$ \\
\hline \multicolumn{3}{c}{$\checkmark=$ Applicable; $-=$ Not applicable. }
\end{tabular}

\section{Experimental Results, Comparison, and Discussion}

After obtaining the parameters for each model, detailed in Appendix A in Tables A1-A9, using the procedure described in Section 3 and identification current profiles described in Section 4, the output voltage accuracy and robustness analysis for the six supercapacitor models described in Section 2 is performed based on statistical metrics, such as relative error and root-mean-square (RMS) error.

Comparative results with identification current profile $i_{1}$ are illustrated in Figure 11a-d for the HPPC test and Figure 11e-h for the ECE15 test. Figure 11a,e show the experimental supercapacitor voltage and the voltages provided by the Stern-Tafel and Zubieta models. Figure 11b,f show the relative error between these models and the experimental data.

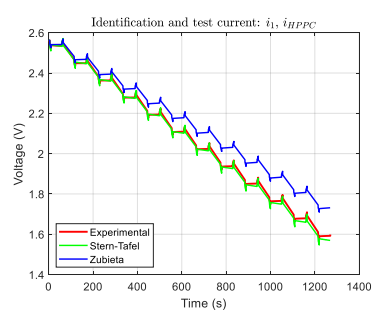

(a)

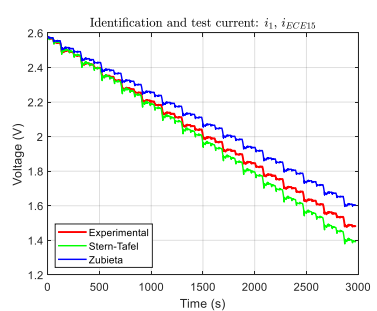

(e)

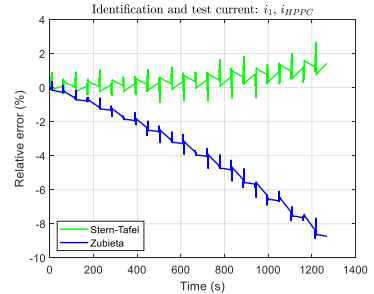

(b)

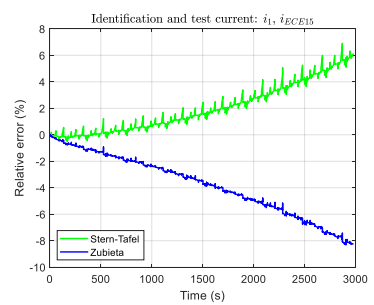

(f)

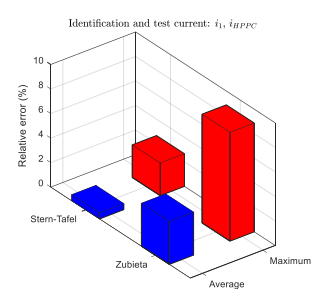

(c)



(g)

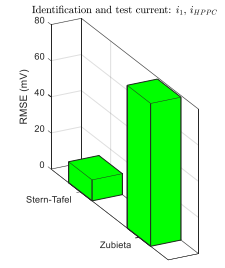

(d)

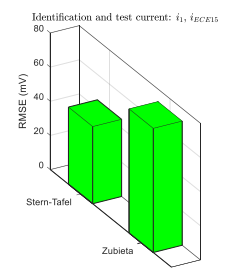

(h)

Figure 11. Experimental data and supercapacitor models time response, relative error (\%), RMS error (mV): (a)-(d) current profile HPPC for $i_{1},(\mathbf{e})-(\mathbf{h})$ current profile ECE15 for $i_{1}$.

Figure 11c,g represent the relative error in percentage. Figure 11d,h show the RMS error in $\mathrm{mV}$. It shows that the Stern-Tafel model has lower error values in comparison with the Zubieta model. In any case, the relative error tendency with the time increase in both models, therefore the accuracy of both models identified with the $i_{1}$ current profile is not proper.

Similar information is shown when current profile $i_{2}$ is used to obtain the model parameters. Figure 12a-d depicted the obtained result for the HPPC test and Figure 12e-h for the ECE15 test. This current profile is applied to five out of the six models, with the exception of the Stern-Tafel model. In this case, the Series model is the best one, since it presents a reduced relative error that maintained with the time. 


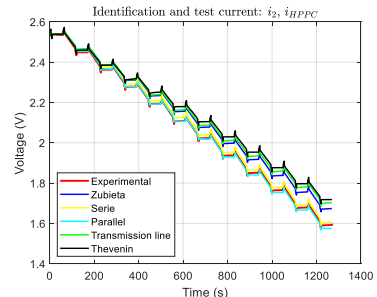

(a)

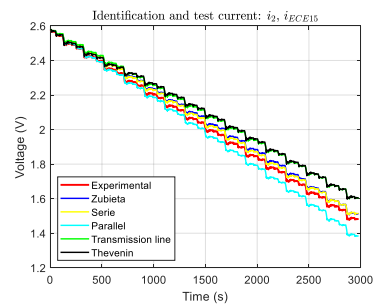

(e)

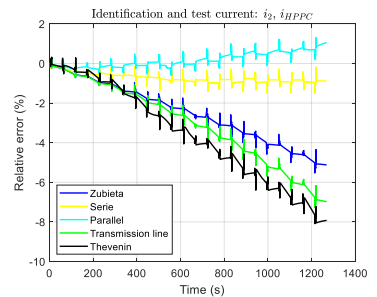

(b)

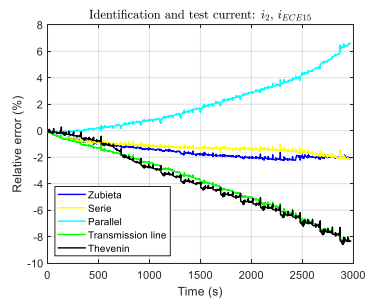

(f)

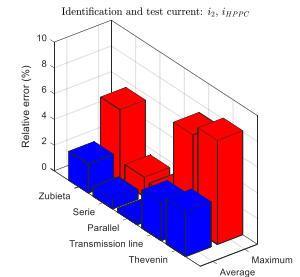

(c)

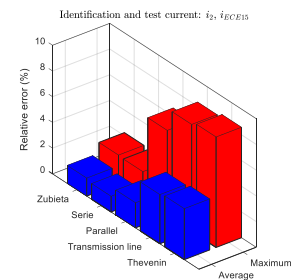

(g)

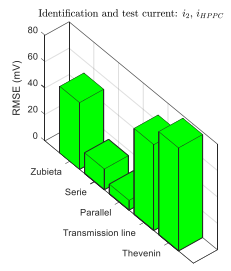

(d)

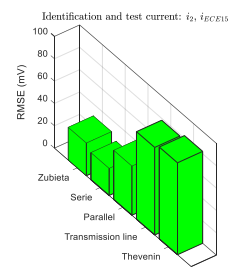

(h)

Figure 12. Experimental data and supercapacitor models time response, relative error (\%), RMS error $(\mathrm{mV})$ : (a)-(d) current profile HPPC for $i_{2},(\mathbf{e})-(\mathbf{h})$ current profile ECE15 for $i_{2}$.

Finally, the result obtained with the current profile $i_{3}$, which is the most dynamic current profile, is depicted in Figure 13a-d for the HPPC test and Figure 13e-h for the ECE15 test. This current profile has been applied to the same models as current profile $i_{2}$. Again, the Serie Model has the best performance, and even the obtained relative error is lower than using the previous current profiles. Nevertheless, the Parallel model, Transmission Line model and Thevenin model get good behaviors.

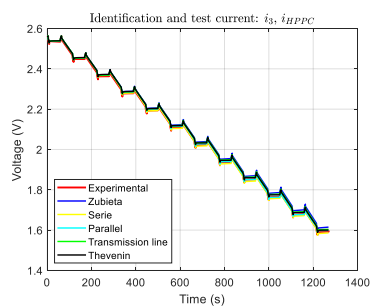

(a)

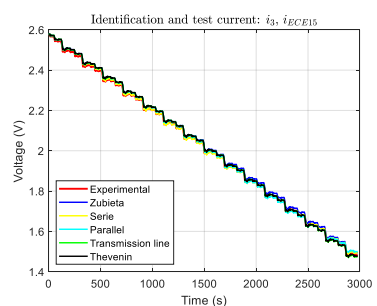

(e)

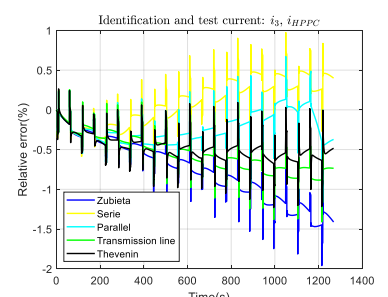

(b)



(f)

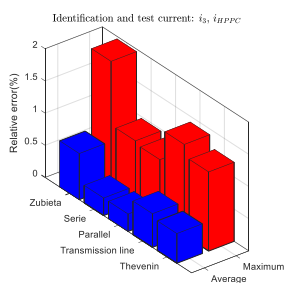

(c)

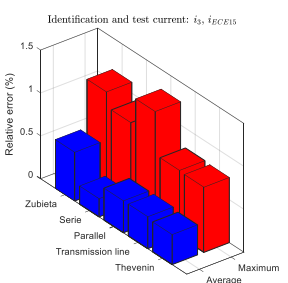

(g)

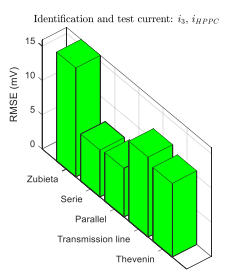

(d)

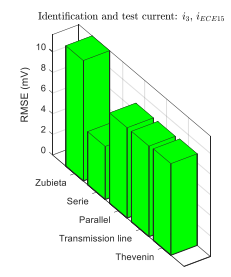

(h)

Figure 13. Experimental data and supercapacitor models time response, relative error (\%), RMS error $(\mathrm{mV})$ : (a)-(d) current profile HPPC for $i_{3},(\mathbf{e})-(\mathbf{h})$ current profile ECE15 for $i_{3}$.

The main conclusions obtained from these results are the following:

- The greater complex identification current profile $i_{3}$ gets greater accuracy for every model in which it can be applied.

- In most cases, the Series model provides the minimum relative error.

- If a simple and basic supercapacitor model has to be used, the best option is to use Zubieta model identified with the current profile $i_{3}$. 
Tables 4-6 include the numeric values for different current profiles identification and the response of each model for HPPC and ECE15 test. These values are those shown in Figures 10-12.

Table 4. The statistical metric with Current Profile $i_{1}$.

\begin{tabular}{ccccccc}
\hline \multirow{3}{*}{ Model } & \multicolumn{3}{c}{ HPPC } & \multicolumn{3}{c}{ ECE15 } \\
\cline { 2 - 7 } & $\begin{array}{c}\text { Maximum } \\
\text { Relative } \\
\text { Error (\%) }\end{array}$ & $\begin{array}{c}\text { Average } \\
\text { Relative } \\
\text { Error (\%) }\end{array}$ & $\begin{array}{c}\text { Root Mean } \\
\text { Square } \\
\text { Error }(\mathbf{m V})\end{array}$ & $\begin{array}{c}\text { Maximum } \\
\text { Relative } \\
\text { Error } \mathbf{( \% )}\end{array}$ & $\begin{array}{c}\text { Average } \\
\text { Relative } \\
\text { Error (\%) }\end{array}$ & $\begin{array}{c}\text { Root Mean } \\
\text { Square } \\
\text { Error (mV) }\end{array}$ \\
\hline Stern-Tafel & 2.6624 & 0.4975 & 11.6037 & 6.9044 & 2.0402 & 45.1645 \\
Zubieta & 8.8702 & 3.5055 & 79.0721 & 8.2994 & 3.3861 & 72.6719 \\
\hline
\end{tabular}

Table 5. The statistical metric with Current Profile $i_{2}$.

\begin{tabular}{ccccccc}
\hline \multirow{2}{*}{ Model } & \multicolumn{3}{c}{ HPPC } & \multicolumn{3}{c}{ ECE15 } \\
\cline { 2 - 7 } & $\begin{array}{c}\text { Maximum } \\
\text { Relative } \\
\text { Error (\%) }\end{array}$ & $\begin{array}{c}\text { Average } \\
\text { Relative } \\
\text { Error (\%) }\end{array}$ & $\begin{array}{c}\text { Root Mean } \\
\text { Square } \\
\text { Error (mV) }\end{array}$ & $\begin{array}{c}\text { Maximum } \\
\text { Relative } \\
\text { Error (\%) }\end{array}$ & $\begin{array}{c}\text { Average } \\
\text { Relative } \\
\text { Error (\%) }\end{array}$ & $\begin{array}{c}\text { Root Mean } \\
\text { Square } \\
\text { Error (mV) }\end{array}$ \\
\hline Zubieta & 5.5291 & 2.2657 & 50.5217 & 2.2409 & 1.4013 & 29.2705 \\
Serie & 1.5156 & 0.7592 & 15.7086 & 2.1871 & 1.2212 & 24.2654 \\
Parallel & 1.2932 & 0.2971 & 7.3963 & 6.6324 & 1.9509 & 43.9770 \\
Transmission line & 7.2856 & 2.9581 & 65.0135 & 8.3307 & 3.8223 & 78.3289 \\
Thevenin & 8.0835 & 3.5226 & 77.9992 & 8.5904 & 3.9647 & 82.2516 \\
\hline
\end{tabular}

Table 6. The statistical metric with Current Profile $i_{3}$.

\begin{tabular}{ccccccc}
\hline \multirow{3}{*}{ Model } & \multicolumn{3}{c}{ HPPC } & \multicolumn{3}{c}{ ECE15 } \\
\cline { 2 - 7 } & $\begin{array}{c}\text { Maximum } \\
\text { Relative } \\
\text { Error (\%) }\end{array}$ & $\begin{array}{c}\text { Average } \\
\text { Relative } \\
\text { Error (\%) }\end{array}$ & $\begin{array}{c}\text { Root Mean } \\
\text { Square } \\
\text { Error (mV) }\end{array}$ & $\begin{array}{c}\text { Maximum } \\
\text { Relative } \\
\text { Error (\%) }\end{array}$ & $\begin{array}{c}\text { Average } \\
\text { Relative } \\
\text { Error (\%) }\end{array}$ & $\begin{array}{c}\text { Root Mean } \\
\text { Square } \\
\text { Error (mV) }\end{array}$ \\
\hline Zubieta & 1.9602 & 0.7170 & 15.8874 & 1.1287 & 0.5673 & 11.6797 \\
Serie & 0.9718 & 0.2728 & 6.8365 & 0.9562 & 0.2119 & 5.1513 \\
Parallel & 0.9263 & 0.2714 & 7.0952 & 1.2706 & 0.3724 & 8.7621 \\
Transmission line & 1.4099 & 0.5227 & 11.6305 & 0.7700 & 0.3722 & 8.7803 \\
Thevenin & 1.2297 & 0.4617 & 10.7354 & 0.7593 & 0.3493 & 8.8829 \\
\hline
\end{tabular}

\section{Conclusions}

This paper describes a parameter identification general procedure with a flexible and interactive interface used to build supercapacitor models in Simulink or Simscape. This procedure enables estimating the different models parameters based on the use of the Optimization Toolbox of Matlab ${ }^{\circledR}$. Once, the procedure steps are explained, the procedure is used to develop a comparative study of six commonly used supercapacitor models. In addition, the procedure enables using different identification current profiles, providing the possibility of analyzing the influence of three different identification current profiles in the accuracy and robustness of every model.

The experimental results obtained from the six models and three different identification current profiles, used to develop the study, show that both the model and the identification current profile are critical to obtaining good accuracy and robustness, which must be maintained over time.

From the comparison between the experimental results and the simulation results obtained using the model, it can be concluded that the greater complexity of the current identification profile, the greater accuracy and robustness of the model. In this case, the most complex identification current profile $i_{3}$ gets the best accuracy for every model in which it can be applied.

In a short simulation period, most models provide enough accuracy results. However, in a long simulation period the differences among models as well as among the current identification profiles 
increase, and models responses cumulate voltage errors and, in some cases, they cannot correctly represent the voltage of the supercapacitor. The Stern-Tafel model is proper for a short simulation and as a first approximation. However, in a long-time simulation, the Series Model represents a good performance, followed by the Parallel Model. In most cases, the Series model provides the minimum relative error. However, the Zubieta model provides a good compromise between complexity and accuracy. Then, if a simple and basic supercapacitor model has to be used, the best option is to use a Zubieta model identified by means of the current profile $i_{3}$.

Author Contributions: Conceptualization, H.M. and A.B.; methodology, A.B.; software, H.M.; validation, A.B., P.Z. and A.L.; formal analysis, C.F.; resources, A.B.; writing-original draft preparation, H.M.; writing-review and editing, P.Z. and A.L.; supervision, C.F.; funding acquisition, A.B.

Funding: This research was funded by the Spanish Ministry of Economy and Competitiveness and ERDF, grant number DPI2014-53685-C2-1-R.

Acknowledgments: This work has been supported by the Ministry of Economy and Competitiveness and FEDER funds through the research project "Storage and Energy Management for Hybrid Electric Vehicles based on Fuel Cell, Battery and Supercapacitors"-ELECTRICAR-AG-(DPI2014-53685-C2-1-R).

Conflicts of Interest: The authors declare no conflicts of interest.

\section{Appendix A. Tables of Supercapacitors Parameter}

Table A1. Stern-Tafel Model Parameters with current profile $i_{1}$.

\begin{tabular}{cc}
\hline Parameter & Value \\
\hline$C(\mathrm{~F})$ & 3000 \\
$R_{d c}(\mathrm{~m} \Omega)$ & 2.1000 \\
$I_{f}(\mathrm{~mA})$ & 5.2000 \\
$V_{n}(\mathrm{~V})$ & 2.7000 \\
$N_{s}$ & 1 \\
$N_{p}$ & 1 \\
$N_{e}^{*}$ & 2 \\
$d(\mathrm{~nm})^{*}$ & 1.0115 \\
$\alpha^{*}$ & $0.3200(0<\alpha<1)$ \\
$\Delta V^{*}$ & 0.4100 \\
\hline$*$ = Estimated parameters.
\end{tabular}

Table A2. Zubieta Model Parameters.

\begin{tabular}{cccc}
\hline \multirow{2}{*}{ Parameter } & \multicolumn{3}{c}{ Current Profile } \\
\cline { 2 - 4 } & $\boldsymbol{i}_{\mathbf{1}}$ & $\boldsymbol{i}_{\mathbf{2}}$ & $\boldsymbol{i}_{\mathbf{3}}$ \\
\hline$R_{0}(\mathrm{~m} \Omega)^{*}$ & 1.1080 & 0.8653 & 0.6504 \\
$C_{0}(\mathrm{~F})^{*}$ & 2290.3000 & 2172.6000 & 2081.7000 \\
$k_{c}(\mathrm{~F} / \mathrm{V})^{*}$ & 244.4400 & 240.5600 & 220.1800 \\
$R_{1}(\Omega)^{*}$ & 16.9130 & 19.9280 & 10.5170 \\
$C_{1}(\mathrm{~F})^{*}$ & 471.1500 & 368.1700 & 111.1500 \\
$R_{2}(\Omega)^{*}$ & 0.6729 & 0.3773 & 3.5770 \\
$C_{2}(\mathrm{~F})^{*}$ & 292.0100 & 176.3200 & 382.0700 \\
$R_{l k}(\mathrm{k} \Omega)^{*}$ & 171210 & 11023 & 51.4030 \\
\hline
\end{tabular}


Table A3. Series Model Parameters with current profile $i_{2}$.

\begin{tabular}{|c|c|c|c|c|c|c|c|c|c|c|c|}
\hline \multirow{2}{*}{ Parameter } & \multicolumn{11}{|c|}{ Voltage (V) } \\
\hline & 0 & 0.330 & 0.6417 & 0.9295 & 1.1977 & 1.4522 & 1.6973 & 1.934 & 2.1622 & 2.3830 & 2.5948 \\
\hline$C_{S}(\mathrm{k} \Omega)^{*}$ & 2.4655 & 2.3629 & 2.5419 & 2.6699 & 2.8260 & 2.8941 & 2.9450 & 2.962 & 3.0666 & 3.1518 & 3.5999 \\
\hline$R_{1}(\mu \Omega) *$ & 581.02 & 470.26 & 563.94 & 546.61 & 540.87 & 507.120 & 544.94 & 238.4 & 0.0080 & 1.3731 & 1.6410 \\
\hline$C_{1}(\mathrm{kF}) *$ & 1.1595 & 1.7094 & 1.0285 & 1.5702 & 1.5695 & 2.1529 & 1.4429 & 0.277 & 265.980 & 65.884 & 87.292 \\
\hline$R_{2}(\mu \Omega)^{*}$ & 0.120 & 58.126 & 14.810 & 25.842 & 43.970 & 108.870 & 0.0164 & 6.128 & 707.200 & 692.73 & 501.860 \\
\hline$C_{2}(\mathrm{~F})^{*}$ & 14.393 & 1324 & 1891.1 & 10714 & 570.42 & 34.5400 & 58.919 & 13.51 & 43.7690 & 161.84 & 54.3090 \\
\hline$R_{3}(\Omega) *$ & & & & & & 10.6610 & & & & & \\
\hline$C_{3}(\mathrm{kF}) *$ & & & & & & 1.0877 & & & & & \\
\hline$R_{4}(\Omega)^{*}$ & & & & & & 14.4660 & & & & & \\
\hline$C_{4}(\mathrm{~F}) *$ & & & & & & 32.5750 & & & & & \\
\hline$R_{l k}(\mathrm{k} \Omega)^{*}$ & & & & & & 5.5436 & & & & & \\
\hline
\end{tabular}

Table A4. Series Model Parameters with current profile $i_{3}$.

\begin{tabular}{|c|c|c|c|c|c|}
\hline \multirow{2}{*}{ Parameter } & \multicolumn{5}{|c|}{ Voltage (V) } \\
\hline & 1.4932 & 1.7931 & 2.0874 & 2.3761 & 2.6618 \\
\hline$C_{S}(\mathrm{k} \Omega)^{*}$ & 2.8890 & 2.9626 & 3.0489 & 3.1745 & 3.1935 \\
\hline$R_{1}(\mu \Omega) *$ & 192.3800 & 460.1300 & 428.0600 & 182.1800 & 437.5600 \\
\hline$C_{1}(\mathrm{~F}) *$ & 15.3320 & 923.8500 & 30.6020 & 9.3121 & 229.6200 \\
\hline$R_{2}(\mu \Omega) *$ & 166.3700 & 1.4114 & 32.8880 & 303.2600 & 99.7610 \\
\hline$C_{2}(\mathrm{kF}) *$ & 0.0309 & 0.2120 & 1.9380 & 1.9937 & 0.1050 \\
\hline$R_{3}(\Omega) *$ & & & 7.6440 & & \\
\hline$C_{3}(\mathrm{kF}) *$ & & & 1.2486 & & \\
\hline$R_{4}(\Omega) *$ & & & 14.0350 & & \\
\hline$C_{4}(\mathrm{~F})^{*}$ & & & 110.7000 & & \\
\hline$R_{l k}(\mathrm{k} \Omega)^{*}$ & & & 1584.4000 & & \\
\hline
\end{tabular}

Table A5. Parallel Model Parameters with current profile $i_{2}$.

\begin{tabular}{|c|c|c|c|c|c|c|c|c|c|c|c|}
\hline \multirow{2}{*}{ Parameter } & \multicolumn{11}{|c|}{ Voltage (V) } \\
\hline & 0.0002 & 0.3301 & 0.6417 & 0.9295 & 1.1977 & 1.4522 & 1.6973 & 1.9337 & 2.1622 & 2.3830 & 2.5948 \\
\hline$C_{1}(\mathrm{kF}) *$ & 11.494 & 56.47 & 86.826 & 0.2254 & 82.203 & 0.00353 & 100.120 & 219.83 & 125.880 & 182.96 & 170 \\
\hline$R_{1}(\Omega) *$ & 18502 & 91.543 & 1980.4 & 15.8680 & 421.90 & 2545.4 & 51657 & 857.68 & 398.850 & 254.02 & 279.950 \\
\hline$C_{2}(\mathrm{~F}) *$ & 561.28 & 258.20 & 362.59 & 239.440 & 57.1310 & 65.969 & 56.8820 & 112.78 & 134.450 & 46.676 & 50.050 \\
\hline $\mathrm{R}_{2}(\mathrm{~m} \Omega)^{*}$ & 0.00358 & 11.937 & 0.3757 & 1.9524 & 155.180 & 137.89 & 117.090 & 14.308 & 13.746 & 4622.1 & 500.020 \\
\hline$C_{3}(\mathrm{~F}) *$ & 1068.9 & 1780.7 & 0.3458 & 43.1960 & 47.3320 & 0.1059 & 665.260 & 8.367 & 12.691 & 30.798 & 25.003 \\
\hline$R_{3}(\mathrm{~m} \Omega)^{*}$ & 2.9311 & 5.5832 & 0.00014 & 0.6223 & 16.946 & 3.0161 & 5.6190 & 1.2579 & 0.01369 & 369.01 & 100 \\
\hline$C_{4}(\mathrm{kF}) *$ & 1.8016 & 0.0452 & 2.4350 & 2.4355 & 2.7939 & 2.7622 & 2.4572 & 3.013 & 3.0641 & 3.3026 & 3.119 \\
\hline$R_{4}(\mathrm{~m} \Omega)^{*}$ & 6.4737 & 8.4052 & 0.1441 & 1.0450 & 0.5837 & 0.6355 & 0.6429 & 0.4083 & 0.3057 & 0.5758 & 0.199 \\
\hline$R_{l k}(\Omega) *$ & 1.6786 & 15.397 & 13.829 & 25.6290 & 11.714 & 13.701 & 17.801 & 17.821 & 16.065 & 16.649 & 18.947 \\
\hline
\end{tabular}

Table A6. Parallel Model Parameters with current profile $i_{3}$.

\begin{tabular}{cccccc}
\hline & \multicolumn{5}{c}{ Voltage (V) } \\
\cline { 2 - 6 } Parameter & $\mathbf{1 . 4 9 3 2}$ & $\mathbf{1 . 7 9 3 1}$ & $\mathbf{2 . 0 8 7 4}$ & $\mathbf{2 . 3 7 6 1}$ & $\mathbf{2 . 6 6 1 8}$ \\
\hline$C_{1}(\mathrm{kF})^{*}$ & 21.1090 & 652.920 & 119.440 & 503.490 & 28.4650 \\
$R_{1}(\Omega)^{*}$ & 0.3961 & 765.50 & 364.790 & 112.370 & 14.1460 \\
$C_{2}(\mathrm{~F})^{*}$ & 59.1990 & 123.90 & 110.42 & 126.430 & 26.3940 \\
$R_{2}(\Omega)^{*}$ & 9.1786 & 0.12605 & 0.11993 & 0.09205 & 0.01963 \\
$C_{3}(\mathrm{~F})^{*}$ & 657.710 & 15.920 & 21.9840 & 17.6280 & 15.6860 \\
$R_{3}(\mathrm{~m} \Omega)^{*}$ & 16.0070 & 4.7105 & 11.4340 & 0.0615 & 12.3470 \\
$C_{4}(\mathrm{kF})^{*}$ & 3.0746 & 2.867 & 2.9347 & 3.0351 & 3.1868 \\
$R_{4}(\mathrm{u} \Omega)^{*}$ & 507.890 & 657.90 & 689.490 & 470.030 & 850.340 \\
$R_{l k}(\Omega)^{*}$ & 120.930 & 768.810 & 6150.30 & 585.340 & 303.670 \\
\hline
\end{tabular}


Table A7. Transmission Line Model Parameters.

\begin{tabular}{ccc}
\hline \multirow{2}{*}{ Parameter } & \multicolumn{2}{c}{ Current Profile } \\
\cline { 2 - 3 } & $\boldsymbol{i}_{2}$ & $\boldsymbol{i}_{3}$ \\
\hline$R_{1}(\mu \Omega)^{*}$ & 826.72 & 575.75 \\
$R_{2}(\mathrm{~m} \Omega)^{*}$ & 115.67 & 2.7568 \\
$R_{3}(\Omega)^{*}$ & 1.3558 & 0.0116 \\
$R_{4}(\Omega)^{*}$ & 3.9621 & 1.5723 \\
$k_{c 1}(\mathrm{~F} / \mathrm{V})^{*}$ & 209.20 & 85.715 \\
$k_{c 2}(\mathrm{~F} / \mathrm{V})^{*}$ & 26.6080 & 21.482 \\
$k_{c 3}(\mathrm{~F} / \mathrm{V})^{*}$ & 47.1510 & 13.4470 \\
$k_{c 4}(\mathrm{~F} / \mathrm{V})^{*}$ & 11.8540 & 15.2340 \\
$C_{1}(\mathrm{~F})^{*}$ & 2303.30 & 2408.90 \\
$C_{2}(\mathrm{~F})^{*}$ & 0.1000 & 5.2926 \\
$C_{3}(\mathrm{~F})^{*}$ & 21.2820 & 120.67 \\
$C_{4}(\mathrm{~F})^{*}$ & 37.9010 & 55.4780 \\
$R_{l k}(\mathrm{k} \Omega)^{*}$ & 111.01 & 13.8080 \\
\hline \multicolumn{2}{c}{$*$ Estimated parameters. }
\end{tabular}

Table A8. Thevenin Model Parameters with $i_{2}$ Current Profile.

\begin{tabular}{cccccccccccc}
\hline \multirow{2}{*}{ Parameter } & \multicolumn{10}{c}{ SOC $\mathbf{( \% )}$} \\
\cline { 2 - 13 } & $\mathbf{0 . 0 1}$ & $\mathbf{1 0}$ & $\mathbf{2 0 . 0 4}$ & $\mathbf{2 9 . 9 6}$ & $\mathbf{3 9 . 9 5}$ & $\mathbf{4 9 . 8 6}$ & $\mathbf{5 9 . 8 9}$ & $\mathbf{6 9 . 7 7}$ & $\mathbf{7 0 . 7 7}$ & $\mathbf{8 9 . 6 7}$ & $\mathbf{9 9 . 6 4}$ \\
\hline OCV $(\mathrm{V})$ & 0.0002 & 0.330 & 0.6417 & 0.9295 & 1.1977 & 1.4522 & 1.6973 & 1.9337 & 2.162 & 2.3830 & 2.5953 \\
$C_{1}(\mathrm{~F})^{*}$ & 17046 & 551.64 & 236.58 & 303.76 & 363.06 & 509.86 & 434.30 & 401.51 & 227.47 & 411.24 & 147.11 \\
$C_{2}(\mathrm{kF})^{*}$ & 119.28 & 29.58 & 35.427 & 30.323 & 39.527 & 22.579 & 20.577 & 771.57 & 11.614 & 94.522 & 19.695 \\
$C_{3}(\mathrm{kF})^{*}$ & 2943.8 & 498.12 & 248.36 & 205.07 & 541.22 & 449.09 & 844.16 & 97.252 & 2507.5 & 703.25 & 3.772 \\
$R_{0}(\mu \Omega)^{*}$ & 723.2 & 431.02 & 0.2476 & 13.381 & 104.41 & 17.20 & 3.7923 & 213.26 & 115.96 & 23.528 & 372.15 \\
$R_{1}(\mathrm{~m} \Omega)^{*}$ & 1.2436 & 0.9416 & 1.2504 & 1.1690 & 1.1998 & 1.3676 & 1.3495 & 1.2395 & 1.0854 & 1.1086 & 1.2487 \\
$R_{2}(\mathrm{~m} \Omega)^{*}$ & 68.622 & 10.261 & 1.1819 & 35.648 & 3.3491 & 0.32405 & 0.4529 & 7.7754 & 14.9250 & 1.6529 & 186.44 \\
$R_{3}(\Omega)^{*}$ & 33.592 & 22.765 & 0.9059 & 2.143 & 2.6865 & 1.9369 & 432.480 & 548140 & 29422 & 558.260 & 555 \\
\hline & \multicolumn{10}{c}{ * Estimated parameters. }
\end{tabular}

Table A9. Thevenin Model Parameters with $i_{3}$ Current Profile.

\begin{tabular}{cccccc}
\hline \multirow{2}{*}{ Parameter } & \multicolumn{5}{c}{ SOC (\%) } \\
\cline { 2 - 6 } & $\mathbf{5 3 . 3 7}$ & $\mathbf{6 4 . 6 8}$ & $\mathbf{7 5 . 9 7}$ & $\mathbf{8 7 . 2 5}$ & $\mathbf{9 8 . 5 9}$ \\
\hline$O C V(\mathrm{~V})$ & 1.4786 & 1.7794 & 2.0742 & 2.365 & 2.6499 \\
$C_{1}(\mathrm{~F})^{*}$ & 0.070731 & 11.1610 & 11.1610 & 12.30 & 123.90 \\
$C_{2}(\mathrm{kF})^{*}$ & 7.2709 & 1.3362 & 0.7907 & 16.107 & 28.906 \\
$C_{3}(\mathrm{MF})^{*}$ & 1929.30 & 0.00769 & 0.00638 & 76.5800 & 9.8952 \\
$R_{0}(\mu \Omega)^{*}$ & 6.5167 & 13.9100 & 39.4740 & 75.8540 & 53.527 \\
$R_{1}(\mu \Omega)^{*}$ & 204.02 & 168.97 & 35.226 & 339.940 & 565.850 \\
$R_{2}(\mu \Omega)^{*}$ & 684.340 & 486.780 & 512.330 & 352.520 & 284.940 \\
$R_{3}(\mu \Omega)^{*}$ & 24.6710 & 4.8491 & 7.8730 & 74.0560 & 0.25154 \\
\hline \multicolumn{5}{c}{$*$ Estimated parameters. }
\end{tabular}

\section{References}

1. Zhang, L.; Hu, X.; Wang, Z.; Sun, F.; Dorrell, D.G. A review of supercapacitor modeling, estimation, and applications: A control/management perspective. Renew. Sustain. Energy Rev. 2018, 81, 1868-1878. [CrossRef]

2. Ristic, M.; Gryska, Y.; McGinley, J.V.; Yufit, V. Supercapacitor energy storage for magnetic resonance imaging systems. IEEE Trans. Ind. Electron. 2014, 61, 4255-4264. [CrossRef]

3. Wu, W.; Partridge, J.; Bucknall, R. Development and Evaluation of a Degree of Hybridisation Identification Strategy for a Fuel Cell Supercapacitor Hybrid Bus. Energies 2019, 12, 142. [CrossRef]

4. Ciccarelli, F.; Di Noia, L.; Rizzo, R. Integration of Photovoltaic Plants and Supercapacitors in Tramway Power Systems. Energies 2018, 11, 410. [CrossRef] 
5. Vazquez, S.; Lukic, S.M.; Galvan, E.; Franquelo, L.G.; Carrasco, J.M. Energy storage systems for transport and grid applications. IEEE Trans. Ind. Electron. 2010, 57, 3881-3895. [CrossRef]

6. Yang, X.; Wen, P.; Xue, Y.; Zheng, T.; Wang, Y. Supercapacitor energy storage based MMC for energy harvesting in mine hoist application. Energies 2017, 10, 1428. [CrossRef]

7. Yang, H.; Zhang, Y. A study of supercapacitor charge redistribution for applications in environmentally powered wireless sensor nodes. J. Power Sources 2015, 273, 223-236. [CrossRef]

8. Wang, H.; Zhou, Q.; Yao, B.; Ma, H.; Zhang, M.; Li, C.; Shi, G. Suppressing the Self-Discharge of Supercapacitors by Modifying Separators with an Ionic Polyelectrolyte. Adv. Mater. Interfaces 2018, 5, 1701547. [CrossRef]

9. Xia, M.; Nie, J.; Zhang, Z.; Lu, X.; Wang, Z.L. Suppressing self-discharge of supercapacitors via electrorheological effect of liquid crystals. Nano Energy 2018, 47, 43-50. [CrossRef]

10. Sarwar, W.; Marinescu, M.; Green, N.; Taylor, N.; Offer, G. Electrochemical double layer capacitor electro-thermal modelling. J. Energy Storage 2016, 5, 10-24. [CrossRef]

11. Wang, H.; Pilon, L. Mesoscale modeling of electric double layer capacitors with three-dimensional ordered structures. J. Power Sources 2013, 221, 252-260. [CrossRef]

12. Lee, J.; Yi, J.; Kim, D.; Shin, C.; Min, K.S.; Choi, J.; Lee, H.Y. Modeling of the Electrical and Thermal Behaviors of an Ultracapacitor. Energies 2014, 7, 8264-8278. [CrossRef]

13. Zhang, L.; Wang, Z.; Hu, X.; Sun, F.; Dorrell, D.G. A comparative study of equivalent circuit models of ultracapacitors for electric vehicles. J. Power Sources 2015, 274, 899-906. [CrossRef]

14. Shi, L.; Crow, M. Comparison of ultracapacitor electric circuit models. In Proceedings of the IEEE Power and Energy Society General Meeting-Conversion and Delivery of Electrical Energy in the 21st Century, Pittsburgh, PA, USA, 20-24 July 2008; pp. 1-6.

15. Xie, C.; Liu, X.; Huang, L.; Fang, W. Modeling of supercapacitor modules in the hybrid powertrain with a nonlinear 3-branch equivalent circuit. Int. J. Energy Res. 2018, 42, 3524-3534. [CrossRef]

16. Miniguano, H.; Raga, C.; Barrado, A.; Lázaro, A.; Zumel, P.; Olías, E. A comparative study and parameterization of electrical battery models applied to hybrid electric vehicles. In Proceedings of the International Conference on Electrical Systems for Aircraft, Railway, Ship Propulsion and Road Vehicles \& International Transportation Electrification Conference (ESARS-ITEC), Toulouse, France, 2-4 November 2016; pp. 1-6.

17. Ceraolo, M.; Lutzemberger, G.; Poli, D. State-Of-Charge Evaluation Of Supercapacitors. J. Energy Storage 2017, 11, 211-218. [CrossRef]

18. Motapon, S.N.; Dessaint, L.A.; Al-Haddad, K. A comparative study of energy management schemes for a fuel-cell hybrid emergency power system of more-electric aircraft. IEEE Trans. Ind. Electron. 2014, 61, 1320-1334. [CrossRef]

19. Zubieta, L.; Bonert, R. Characterization of double-layer capacitors for power electronics applications. IEEE Trans. Ind. Appl. 2000, 36, 199-205. [CrossRef]

20. Wu, C.; Hung, Y.; Hong, C. On-line supercapacitor dynamic models for energy conversion and management. Energy Convers. Manag. 2012, 53, 337-345. [CrossRef]

21. Quintáns, C.; Iglesias, R.; Lago, A.; Acevedo, J.M.; Martínez-Peñalver, C. Methodology to obtain the voltage-dependent parameters of a fourth-order supercapacitor model with the transient response to current pulses. IEEE Trans. Power Electron. 2017, 32, 3868-3878. [CrossRef]

22. Noh, S.; Choi, J.; Kim, H.C.; Lee, E.K. PSIM Based electric modeling of supercapacitors for line voltage regulation of electric train system. In Proceedings of the EEE 2nd International Power and Energy Conference, Johor Bahru, Malaysia, 1-3 December 2008; pp. 855-859.

23. Michalczuk, M.; Grzesiak, L.M.; Ufnalski, B. Experimental parameter identification of battery-ultracapacitor energy storage system. In Proceedings of the IEEE 24th International Symposium on Industrial Electronics (ISIE), Buzios, Brazil, 3-5 June 2015; pp. 1260-1265.

24. Kang, J.; Wen, J.; Jayaram, S.H.; Yu, A.; Wang, X. Development of an equivalent circuit model for electrochemical double layer capacitors (EDLCs) with distinct electrolytes. Electrochim. Acta 2014, 115, 587-598. [CrossRef]

25. Xu, N.; Riley, J. Nonlinear analysis of a classical system: The double-layer capacitor. Electrochem. Commun. 2011, 13, 1077-1081. [CrossRef]

26. Oldham, K.B. A Gouy-Chapman-Stern model of the double layer at a (metal)/(ionic liquid) interface. J. Electroanal. Chem. 2008, 613, 131-138. [CrossRef] 
27. Conway, B.E.; Pell, W.; Liu, T. Diagnostic analyses for mechanisms of self-discharge of electrochemical capacitors and batteries. J. Power Sources 1997, 65, 53-59. [CrossRef]

28. Ji, H.; Zhao, X.; Qiao, Z.; Jung, J.; Zhu, Y.; Lu, Y.; Zhang, L.L.; MacDonald, A.H.; Ruoff, R.S. Capacitance of carbon-based electrical double-layer capacitors. Nat. Commun. 2014, 5, 3317. [CrossRef]

29. Faranda, R. A new parameters identification procedure for simplified double layer capacitor two-branch model. Electr. Power Syst. Res. 2010, 80, 363-371. [CrossRef]

30. Yang, H.; Zhang, Y. Characterization of supercapacitor models for analyzing supercapacitors connected to constant power elements. J. Power Sources 2016, 312, 165-171. [CrossRef]

31. Solano, J.; Hissel, D.; Pera, M.C. Modeling and parameter identification of ultracapacitors for hybrid electrical vehicles. In Proceedings of the IEEE Vehicle Power and Propulsion Conference (VPPC), Beijing, China, 15-18 October 2013; pp. 1-4.

32. Kim, S.H.; Choi, W.; Lee, K.B.; Choi, S. Advanced dynamic simulation of supercapacitors considering parameter variation and self-discharge. IEEE Trans. Power Electron. 2011, 26, 3377-3385.

33. Buller, S.; Karden, E.; Kok, D.; De Doncker, R. Modeling the dynamic behavior of supercapacitors using impedance spectroscopy. In Proceedings of the Conference Record of the 2001 IEEE Industry Applications Conference. 36th IAS Annual Meeting (Cat. No.01CH37248), Chicago, IL, USA, 30 September-4 October 2001; Volume 4, pp. 2500-2504.

34. Musolino, V.; Piegari, L.; Tironi, E. New Full-Frequency-Range Supercapacitor Model With Easy Identification Procedure. IEEE Trans. Ind. Electron. 2013, 60, 112-120. [CrossRef]

35. Signorelli, R.; Ku, D.C.; Kassakian, J.G.; Schindall, J.E. Electrochemical Double-Layer Capacitors Using Carbon Nanotube Electrode Structures. Proc. IEEE 2009, 97, 1837-1847. [CrossRef]

36. Wei, T.; Qi, X.; Qi, Z. An improved ultracapacitor equivalent circuit model for the design of energy storage power systems. In Proceedings of the International Conference on Electrical Machines and Systems (ICEMS), Seoul, South Korea, 8-11 October 2007; pp. 69-73.

37. Miller, J.M.; McCleer, P.J.; Cohen, M. Ultracapacitors as Energy Buffers in a Multiple Zone Electrical Distribution System; Maxwell Technologies: San Diego, CA, USA, 2004.

38. Lajnef, W.; Vinassa, J.M.; Briat, O.; Azzopardi, S.; Woirgard, E. Characterization methods and modelling of ultracapacitors for use as peak power sources. J. Power Sources 2007, 168, 553-560. [CrossRef]

39. Yang, H. Estimation of Supercapacitor Charge Capacity Bounds Considering Charge Redistribution. IEEE Trans. Power Electron. 2018, 33, 6980-6993. [CrossRef]

40. Schaeffer, E.; Auger, F.; Shi, Z.; Guillemet, P.; Loron, L. Comparative analysis of some parametric model structures dedicated to EDLC diagnosis. IEEE Trans. Ind. Electron. 2016, 63, 387-396. [CrossRef]

41. Dougal, R.; Gao, L.; Liu, S. Ultracapacitor model with automatic order selection and capacity scaling for dynamic system simulation. J. Power Sources 2004, 126, 250-257. [CrossRef]

42. Parvini, Y.; Siegel, J.B.; Stefanopoulou, A.G.; Vahidi, A. Supercapacitor electrical and thermal modeling, identification, and validation for a wide range of temperature and power applications. IEEE Trans. Ind. Electron. 2016, 63, 1574-1585. [CrossRef]

43. Isermann, R.; Münchhof, M. Identification of Dynamic Systems: An Introduction with Applications; Springer Science \& Business Media: Berlin, Germany, 2010.

44. Wang, Y.; Liu, C.; Pan, R.; Chen, Z. Modeling and state-of-charge prediction of lithium-ion battery and ultracapacitor hybrids with a co-estimator. Energy 2017, 121, 739-750. [CrossRef]

45. MathWorks. Simulink ${ }^{\circledR}$ Design Optimization User 's Guide; MathWorks: Natick, MA, USA, 2018.

46. Jackey, R.A.; Plett, G.L.; Klein, M.J. Parameterization of a Battery Simulation Model Using Numerical Optimization Methods; Technical Report; SAE: Warrendale, PA, USA, 2009.

47. Jackey, R.; Saginaw, M.; Sanghvi, P.; Gazzarri, J.; Huria, T.; Ceraolo, M. Battery Model Parameter Estimation Using a Layered Technique: An Example Using a Lithium Iron Phosphate Cell; Technical Report; SAE: Warrendale, PA, USA, 2013.

48. Chakraborty, U.K.; Abbott, T.E.; Das, S.K. PEM fuel cell modeling using differential evolution. Energy 2012, 40, 387-399. [CrossRef]

49. Chakraborty, U.K. Static and dynamic modeling of solid oxide fuel cell using genetic programming. Energy 2009, 34, 740-751. [CrossRef]

50. MathWorks. Simulink ${ }^{\circledR}$ Design Optimization Getting Started Guide; MathWorks: Natick, MA, USA, 2019. 
51. Burke, A. Ultracapacitor technologies and application in hybrid and electric vehicles. Int. J. Energy Res. 2010, 34, 133-151. [CrossRef]

52. He, H.; Xiong, R.; Zhang, X.; Sun, F.; Fan, J. State-of-charge estimation of the lithium-ion battery using an adaptive extended Kalman filter based on an improved Thevenin model. IEEE Trans. Veh. Technol. 2011, 60, 1461-1469.

53. Raga, C.; Barrado, A.; Lázaro, A.; Quesada, I.; Sanz, M.; Zumel, P. Driving profile and fuel cell minimum power analysis impact over the size and cost of fuel cell based propulsion systems. In Proceedings of the 9th International Conference on Compatibility and Power Electronics (CPE), Costa da Caparica, Portugal, 24-26 June 2015; pp. 390-395.

(C) 2019 by the authors. Licensee MDPI, Basel, Switzerland. This article is an open access article distributed under the terms and conditions of the Creative Commons Attribution (CC BY) license (http://creativecommons.org/licenses/by/4.0/). 